Manuscript submitted July 28, 2014.

\title{
Transformation of Lamellar Structures in Equal Channel Angular Pressing: Geometric Model and Application to Nickel Aluminum Bronze
}

\author{
C.J. Barr ${ }^{1,2}$, D.T. McDonald ${ }^{1,2}$, and K. Xia ${ }^{1,2} *$ \\ 1. Department of Mechanical Engineering, University of Melbourne, Victoria 3010, Australia \\ 2. Defence Materials Technology Centre, Hawthorn, Victoria 3122, Australia
}

\begin{abstract}
Nickel aluminum bronze (NAB) with a duplex structure was subjected to equal channel angular pressing (ECAP). Samples were pressed for up to four passes at $673 \mathrm{~K}\left(400^{\circ} \mathrm{C}\right)$ using routes $\mathrm{A}, \mathrm{B}_{\mathrm{A}}$, $\mathrm{B}_{\mathrm{C}}$ and $\mathrm{C}$, respectively, and the evolution of the microstructures characterised. A detailed geometric model was developed to enable systematic and quantitative analysis of the transformation of the lamellar structure during ECAP. Depending on their orientations before each ECAP pass, the lamellae were either stretched, leading to fragmentation, or compressed, resulting in buckling and spheroidisation at locations of high curvature. Thanks to the continuous rotation of lamellae into the stretching orientations in route A and the non-plane strain deformation in the two B routes, they are demonstrated to be the most effective in breaking down the lamellar structure. In contrast, partial restoration due to redundant strain in route $\mathrm{C}$ makes it least efficient. The model applies generally to materials with a duplex structure, such as NAB and low and medium carbon steels, consisting of a hard and brittle lamellar phase and a softer and ductile matrix phase.
\end{abstract}

Keywords: Equal channel angular pressing, copper alloys, modelling, microstructure, lamellar structure. 
* Corresponding authors: c.barr2@student.unimelb.edu.au, k.xia@unimelb.edu.au 


\section{Introduction}

Aluminium bronze is a class of copper alloys highly favoured for use in corrosive environments thanks to a unique protective surface layer of dual copper and aluminium oxides [1-3]. Both strength and corrosion resistance of aluminium bronze are improved with increasing $\mathrm{Al}$ content although the benefit is limited by the formation of an adverse $\gamma_{2}$ phase $\left(\mathrm{Cu}_{9} \mathrm{Al}_{4}\right)$ at $>8.8 \mathrm{wt} . \%$ Al which embrittles Al-bronze [4] and causes selective corrosion due to its higher Al content [1-3]. Nickel aluminium bronze (NAB) is the strongest of this class, as additions of iron and nickel suppress the formation of the $\gamma_{2}$ phase, allowing the maximum Al content to 11 wt.\% [5]. However, these additions also lead to a highly complex array of precipitates in the primary $\alpha$ matrix, identified as $\kappa_{\mathrm{I}}$ to $\kappa_{\mathrm{IV}}$ depending on composition and morphology. Large rosettes of $\mathrm{Fe}_{3} \mathrm{Al}$ are designated as $\kappa_{\mathrm{I}}$ or $\kappa_{\text {II }}$ (distinguishable by size and location [6]), while the lamellar NiAl in the eutectoid structure as $\kappa_{\mathrm{III}}$ and the fine $\mathrm{Fe}_{3} \mathrm{Al}$ based precipitates in the primary $\alpha$ matrix as $\kappa_{\mathrm{IV}}[2]$. (Detailed descriptions of the various phases can be found in $[2,7]$.) The nickel rich $\kappa_{\text {III }}$ phase is of particular concern since, unlike the three iron rich $\kappa$-phases, it causes selective corrosion at the $\alpha-\kappa_{\text {III }}$ interface, accelerating the loss of material during exposure to sea water owing to the continuous nature of the lamellar $\kappa_{\text {III }}$ $[8,9]$. The attack is especially severe under crevice corrosion conditions with deep penetration beneath the surface [10]. In addition, the presence of $\kappa_{\text {III }}$ leads to a highly inhomogeneous cast microstructure, providing a large number of sites for stress concentration and resulting in reduced ductility. Therefore, significant improvements in mechanical and corrosion performances can be gained by disrupting the continuity of the lamellar $\kappa_{\mathrm{III}}$.

Severe plastic deformation (SPD) offers a unique opportunity to both break the lamellar structure [11-15] and greatly enhance the strength of NAB through grain refinement [16]. The ultrafine grained (UFG) structure obtained by SPD has also been known to enhance corrosion resistance on its own right in several other alloys [17]. Of the available SPD processes, equal channel angular pressing (ECAP) is widely used for its ability to produce bulk UFG materials [16]. 
However, only limited studies have been conducted on the effect of ECAP on lamellar structures. Wang et. al. [11] investigated the breakdown of lamellar structures during ECAP of a eutectic Al33 wt.\% $\mathrm{Cu}$ alloy. Shear was found to concentrate on and cut through the lamellae, forming highly distorted pathways which subdivided the lamellar colonies into smaller sections and drove the transformation to a globular morphology. Similar observations were made in high carbon steels [12], as both alloys contained mostly lamellar colonies. In contrast, materials with a duplex microstructure of lamellar colonies and softer matrix grains did not show the same cutting phenomena. In low $[13,14]$ and medium [15] carbon steels (containing a mixture of ferrite grains and pearlite colonies), the lamellae were transformed into either 'severely necked' fragments or highly curled 'wavy' plates, depending on their orientations to the shear plane [14]. However, no quantitative and systematic analysis has been conducted in either the fully lamellar or the duplex microstructure, especially on the effect of lamellar orientations. Moreover, there is a lack of comprehensive comparison between the lamellar structures resulting from various ECAP routes, with the above investigations focusing on either route $B_{C}[11]$ or route $C[14,15]$. The selection of ECAP route has already been shown to play an important role in the development of grain structure and morphology [18], and is expected to play an equally important role in the deformation of lamellar structures. Although Tian et al. [19] used all four routes in the processing of a Cu-8 wt.\% Ag hypoeutectic alloy, the material was hot forged prior to ECAP and the lamellae had either been already altered or formed preferred orientations, making any orientation effect unobservable. In all the cases, a systematic and quantitative approach is lacking.

As the enhanced performances of ECAP processed NAB depend on efficient and favourable transformations of the lamellar $\kappa_{\text {III }}$ and the lamellar structures are generally important in many engineering materials such as carbon steels, better understanding of the breakdown of lamellar structures during deformation is desirable. In two previous reports of the present investigation, the benefits of ECAP processing to mechanical properties have been demonstrated [20] and some 
effects of lamellar orientations and ECAP routes on resulting microstructures qualitatively described [21]. In this further study, a more comprehensive understanding is provided by (1) systematically and quantitatively characterising the evolution of the $\kappa_{\text {III }}$ phase in NAB during ECAP via various routes, (2) establishing a geometrical model to analyze and predict the morphological changes of the $\kappa_{\text {III }}$ phase with a view to exploring the mechanisms for lamellar transformations, and (3) determining the most effective route for eliminating the lamellar structure through ECAP. The analysis and conclusions are expected to be generally applicable to evolution of lamellar structures during shear deformation.

\section{Experimental material and procedures}

A cast NAB plate with a composition of $\mathrm{Cu}-8.8 \mathrm{Al}-4.4 \mathrm{Fe}-5.2 \mathrm{Ni}-1.1 \mathrm{Mn}$ (wt\%) was supplied by VEEM Australia, after heat treatment at $984 \mathrm{~K}\left(675^{\circ} \mathrm{C}\right)$ for $6 \mathrm{~h}$. Such a heat treatment is necessary to fully transform any retained $\beta^{\prime}$ phase into $\alpha+\kappa_{\text {III }}$, and is known to improve corrosion resistance [2]. The plate was machined into bars of $8 \times 8 \times 100 \mathrm{~mm}$ for ECAP. These specimens were lubricated with a $0.3 \mathrm{~mm}$ layer of solid graphite and inserted into a $90^{\circ}$ ECAP die with a cross section of $9 \times 9 \mathrm{~mm}$ and inner $(I)$ and outer $(O)$ radii, at the corner, of 5 and $3 \mathrm{~mm}$, respectively, as shown in Fig. 1. The die was heated to $673 \mathrm{~K}\left(400^{\circ} \mathrm{C}\right)$ and after the temperature stabilised, pressing was conducted at $5 \mathrm{~mm} / \mathrm{min}$. In addition to a forward plunger in the entrance channel, a back plunger was placed in the exit channel to provide a constant back pressure of $50 \mathrm{MPa}$ during ECAP. Samples were pressed to a maximum of 4 passes using routes $A, B_{A}, B_{C}$ and $C$, respectively and quenched in water upon retrieval from the die. Microstructures were examined using scanning electron microscopy (SEM, backscattered electron imaging at an accelerating voltage of $15 \mathrm{kV}$ ) on samples prepared to $0.5 \mu \mathrm{m}$ diamond polish before finishing with colloidal silica. Each sample was carefully oriented so that the $x$-axis was placed horizontally, pointing to the exit direction of ECAP, and the $z$-axis vertically upwards, as shown in Fig. 1. 


\section{Results}

\subsection{Microstructures}

\subsubsection{As-received microstructure}

The as-received microstructure is displayed in Fig. 2, showing (arrowed) the rosette-shaped $\kappa_{\text {II }}$ particles randomly dispersed in the eutectoid region, the lamellar $\kappa_{\text {III }}$ forming the eutectoid structure, and the fine $\kappa_{\mathrm{IV}}$ precipitates in the primary $\alpha$. (The large $\kappa_{\mathrm{I}}$ particles were rarely observed.) No retained $\beta$ was present owing to the previous heat treatment of the plate. The primary $\alpha$ formed by dendritic growth during casting had random orientations, resulting in randomly oriented lamellae which are known to grow perpendicular to the primary $\alpha$ interface [2].

\subsubsection{Microstructures after ECAP for one pass}

The microstructures after one pass of ECAP are shown in Fig. 3. The well-defined and randomly oriented lamellar structure in the as-received material became oriented in certain directions and some were fragmented or distorted depending on the orientations. In the most common orientation, the eutectoid structure was stretched into thin sections with their long axes aligned close to $\theta^{\prime}=22^{\circ}$ (measured anti-clockwise from the x-axis as in Fig. 1), as shown in Fig. 3 a. The lamellar $\kappa_{\text {III }}$ lying in this direction became highly fragmented (arrow 1 and inset), with the individual $\kappa_{\mathrm{III}}$ fragments lining up in streams along the former lamellar planes. The spacing between these streams was considerably smaller than the original lamellar spacing before deformation, suggesting the lamellae had been compressed perpendicular to their planes. Some of these $\kappa_{\text {III }}$ fragments were apparently coarsened perhaps through spheroidisation, identifiable by the surrounding area of $\kappa_{\mathrm{IV}}$-precipitate free eutectoid $\alpha$ (arrow 2). The second prominent orientation was perpendicular to the $\theta^{\prime}=22^{\circ}$ direction just discussed, characterised by shorter and thicker eutectoid colonies as illustrated in Fig. $3 \mathrm{~b}$. The lamellar $\kappa_{\mathrm{III}}$ in this orientation was mostly unbroken, but rather became highly distorted and bent at multiple locations (e.g. arrow 1 in Fig. 3b). This 
'buckling' of the lamellar $\kappa_{\text {III }}$ appeared to be shared amongst the adjacent laths and near stress concentrators such as the larger $\kappa_{\mathrm{II}}$ (arrow 2) or in regions of fewer laths (arrow 3), compared to places with a large number of laths (arrow 4). Finally, when the lamellae were oriented at $\theta^{\prime} \approx 45^{\circ}$ (Fig. 3c) or $\theta^{\prime} \approx 0^{\circ}(3 \mathrm{~d})$, neither fragmentation nor buckling was apparent, leaving largely straight and undistorted plates (arrowed).

\subsubsection{Microstructures after ECAP via route A}

From the second pass, the effects of the various ECAP routes come into play. In route A with no rotation of the sample between passes, the microstructure continues to evolve in the same way as that in the first pass. The microstructures after multiple passes of ECAP via route A are shown in Fig. 4. After 2 passes, both the lamellar colonies (no matter what the orientations of the lamellae in them) and the primary $\alpha$ grains were further stretched to form a distinctive layered

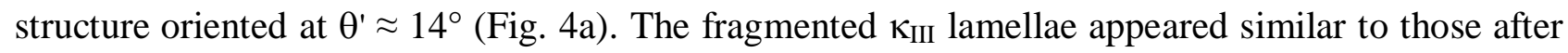
one pass although the spacing between the fragmented streams became smaller (arrow 1). The number of the colonies with buckled plates was noticeably smaller with much larger lamellar spacing (arrow 2), and the lamellae often displayed tails of fragmented $\kappa_{\mathrm{III}}$ when the orientation was closer to the fragmentation direction (arrow 3). In larger colonies with a buckling orientation, the lamellae became increasingly warped (arrow 1 in Fig. 4b) with signs of spheroidisation (arrow 2). After 4 passes (Fig. 4c), the lamellar structure was completely transformed with all the original $\kappa_{\text {III }}$ plates fragmented and/or spheroidised. However, the layered structure of the transformed colonies and the primary $\alpha$ grains was still recognisable, oriented at a further reduced angle of $\theta^{\prime} \approx 6^{\circ}$ to the exit direction and with very small spacing between layers. Furthermore, the size of the fragmented $\kappa_{\text {III }}$ particles was now comparable to that of the fine $\kappa_{\text {IV }}$ precipitates in the primary $\alpha$, making them less distinguishable.

\subsubsection{Microstructures after ECAP via routes $B_{A}$ and $B_{C}$}


The microstructure after 2 passes (the same for routes $\mathrm{B}_{\mathrm{A}}$ and $\mathrm{B}_{\mathrm{C}}$ ) is shown in Fig. 5a, and the ones after 4 passes in Figs. $5 b$ and $5 c$ for routes $B_{A}$ and $B_{C}$, respectively. The microstructure remained highly directional after 2 passes (Fig. 5a), but did not display the distinctive layers seen after 2 passes via route A (Fig. 4a). Broken $\kappa_{\text {III }}$ (arrow 1) was similar to that after one pass, although the fragmented streams were now oriented at $\theta^{\prime} \approx 25^{\circ}$ rather than $\theta^{\prime} \approx 22^{\circ}$. The 2 pass $\mathrm{B}$ route microstructure also consisted of regions of extremely fine spherical particles (arrow 2), in addition to the coarse spheroids seen on the first pass (arrow 3). The orientation of the streams was reduced to $\theta^{\prime} \approx 17^{\circ}$ after 4 passes of route $\mathrm{B}_{\mathrm{A}}($ Fig. $5 \mathrm{~b})$, with the fragments finer and more rounded than on previous passes. The microstructure after 4 passes via route $B_{C}($ Fig. $5 \mathrm{c})$ was similar to that via $B_{A}$ except that the orientation of the layers was increases to $\theta^{\prime} \approx 60^{\circ}$.

\subsubsection{Microstructures after ECAP via route C}

The microstructures after 2 passes via route $C$ are shown in Figs. $6 a$ and 6 , after 3 passes in Figs. $6 \mathrm{c}$ and $6 \mathrm{~d}$, and after 4 passes in Fig. 6e. Unlike the other routes, 2 passes via route $\mathrm{C}$ did not result in further breakdown of the lamellae. Instead, some lamellae seemed to have been "reformed" after fragmentation in the first pass (Fig. 6a). On closer inspection, the individual fragments were still visible by the numerous hairline cracks along the laths (inset). However, it should be noted that the reformed lamellae exhibited a much finer spacing than that in the as-received material. In other cases, some lamellae appeared intact with no cracking (arrow 1 in Fig. 6b) and some remained buckled although possibly to a less extent (arrow 2). Near the intersections of differently oriented laths that had been distorted, clusters of spheroidised $\kappa_{\text {III }}$ (arrow 3) were often observed, which appeared similar in size to those observed after 1 pass and usually surrounded by numerous fine fragments of $\kappa_{\mathrm{III}}$. After 3 passes, the microstructure was directional again (Fig. 6c), similar to that after one pass, although the streams of fragmented $\kappa_{\text {III }}$ were much finer than previously (arrowed in Fig. 6c). The lamellae undergoing buckling (Fig. 6d) remained so, but appeared significantly more warped than after a single pass. After 4 passes (Fig. 6e), the lamellae underwent a second 
reformation which was less complete than that taking place on the second pass. The breakdown into coarse (arrow 1 in Fig. 6e) and fine (arrow 2) spheroids prevented $\kappa_{\text {III }}$ from realigning into a lamellar structure. Furthermore, regions of intact lamellae appeared to be separated by bands of broken lamellae (arrow 3) or regions of misaligned coarse breakages (arrow 4), features not seen in other routes. In general, route $\mathrm{C}$ resulted in a less homogeneous microstructure compared to routes $\mathrm{A}, \mathrm{B}_{\mathrm{A}}$ and $\mathrm{B}_{\mathrm{C}}$.

\section{Discussion}

ECAP has been shown to be effective in eliminating the lamellar structure in NAB. Further, it has been demonstrated that whether a particular lamella is fragmented, buckled or almost intact after ECAP deformation depends on its orientation in the entrance channel before shearing, and that the efficiency of lamellar breakdown is dependent on the route used. In particular, the various ECAP routes appear to result in different evolutions of the microstructure in terms of both the $\kappa_{\text {III }}$ morphology and orientation. In the following discussion, a systematic model based on geometric analysis is developed first, which is then used to explain the experimental observations with a view to understanding various mechanisms which govern the breakdown of the lamellar phase.

\subsection{Geometric model for transformation of lamellae in ECAP}

Several simple geometric models have been widely used to describe the basic shear characteristics of ECAP $[16,22]$. These models generally assume, under ideal conditions with sharp corners, an infinitesimally thin shear plane at the channel intersection which separates the material flowing in parallel to the entrance channel and that flowing out parallel to the exit channel. Such a model has been successful in predicting the shear flow lines in ECAP [23]. However, in the general case of an ECAP die with curved corners, modifications are needed as the shear now takes place over a wide zone rather than a sharp plane [24] and the material flow at the channel intersection is altered. In an ideal sharp cornered $90^{\circ}$ die, the material flow turns sharply at the intersection plane 
while in a round cornered die, the flow follows curved lines defined by the curvatures of the corners. It can be assumed that the shear deformation zone is bordered by two planes, one connecting the curve starting points at the inner and outer corners and the other connecting the finishing points [24], as illustrated in Fig. 1.

The flow pattern in this more general case (also the case in the present investigation) can be described by setting up the coordination system shown in Fig. 7, with the origin placed at the outer corner of an equivalent square angled die and $x$ and $z$ axes oriented towards the exit and entrance channels, respectively. The widths of the channels are both $w$ and the inner and outer radii are $I$ and $O$, respectively. The path of an element at an initial position of $\left(x_{0}, z_{\mathrm{o}}\right)$ and travelling at a constant speed $\mathrm{v}$ can then be analysed as follows.

For a random point $\left(x_{0}, z_{0}\right)$ in the entrance channel, its travel paths in the entrance channel, the shear zone, and the exit channel are $P_{1}, P_{2}$ and $P_{3}$, respectively, as shown in Fig. 7. The shear zone border along its path in the entrance channel $\left(\mathrm{SZB}_{\mathrm{Z}}\right)$ is defined by

$$
z\left(x=x_{o}\right)=\operatorname{SZB}_{\mathrm{Z}}\left(x_{o}\right)=\frac{W+I-O}{W} \cdot x_{o}+O
$$

and by symmetry, the shear zone border in the exit channel $\left(\mathrm{SZB}_{\mathrm{X}}\right)$ is defined by

$$
x\left(z=x_{o}\right)=\operatorname{SZB}_{\mathrm{X}}\left(x_{o}\right)=\frac{W+I-O}{W} \cdot x_{o}+O
$$

At $z>\mathrm{SZB}_{\mathrm{Z}}$ (i.e. before entering the shear zone), the path of this element (i.e. segment $P_{1}$ ) is described by

$$
\begin{gathered}
x=x_{0} \\
z=z_{0}-\mathrm{vt}_{1}
\end{gathered}
$$

where $t_{1}$ is the time travelled from the starting position $\left(x_{0}, z_{0}\right)$. When the element travels inside the shear zone, its path (segment $\left.P_{2}\right)$ defined by $\mathrm{R}\left(x_{\mathrm{o}}\right)$, is determined by 


$$
\begin{gathered}
\mathrm{x}=\mathrm{x}_{\mathrm{o}}+\mathrm{R}\left(\mathrm{x}_{\mathrm{o}}\right)\left[1-\cos \frac{\mathrm{vt}_{2}}{\mathrm{R}\left(\mathrm{x}_{\mathrm{o}}\right)}\right] \\
\mathrm{z}=\mathrm{SZB}_{Z}\left(\mathrm{x}_{\mathrm{o}}\right)-\mathrm{R}\left(\mathrm{x}_{\mathrm{o}}\right) \cdot \sin \frac{\mathrm{vt}_{2}}{\mathrm{R}\left(\mathrm{x}_{\mathrm{o}}\right)}
\end{gathered}
$$

where $t_{2}$ is the time from entering the shear zone and

$$
R\left(x_{0}\right)=\operatorname{SZB}\left(x_{0}\right)-x_{0}=\left(\frac{I-O}{w}\right) x_{0}+0
$$

When it travels outside of the shear zone in the exit channel, i.e. when $x>\mathrm{SZB}_{\mathrm{X}}\left(\operatorname{segment} P_{3}\right)$, the path follows

$$
\begin{gathered}
x=\operatorname{SZB}_{X}\left(x_{0}\right)+\mathrm{vt}_{3} \\
z=x_{\mathrm{o}}
\end{gathered}
$$

where $t_{3}$ is the time travelled from $S Z B$. Together, these three segments $\left(P_{1}, P_{2}\right.$ and $\left.P_{3}\right)$ describe the movement of the element $\left(x_{0}, z_{0}\right)$ during ECAP deformation. The lengths of these segments are

$$
\begin{gathered}
\mathrm{P}_{1}=\mathrm{z}_{\mathrm{o}}-\mathrm{SZB}_{Z}\left(\mathrm{x}_{\mathrm{o}}\right) \\
\mathrm{P}_{2}=\frac{\pi}{2} \cdot \mathrm{R}\left(\mathrm{x}_{\mathrm{o}}\right) \\
\mathrm{P}_{3}=\mathrm{x}_{\mathrm{o}}{ }^{\mathrm{F}}-\operatorname{SZB}_{X}\left(\mathrm{x}_{\mathrm{o}}\right)
\end{gathered}
$$

where $x_{o}{ }^{F}$ is the final position of the element in the exit channel.

Now, consider two random points in the entrance channel before the shear zone: $\left(x_{1}, z_{1}\right)$ and $\left(x_{2}, z_{2}\right)$. They will travel to their final positions in the exit channel: $\left(x_{1}{ }^{F}, z_{1}{ }^{F}\right)$ and $\left(x_{2}{ }^{F}, z_{2}{ }^{F}\right)$. For $\left(x_{1}\right.$, $z_{1}$ ), the travel lengths are

$$
\begin{gathered}
\mathrm{P}_{1}=\mathrm{z}_{1}-\operatorname{SZB}_{Z}\left(\mathrm{x}_{1}\right) \\
\mathrm{P}_{2}=\frac{\pi}{2} \cdot \mathrm{R}\left(\mathrm{x}_{1}\right)
\end{gathered}
$$




$$
\mathrm{P}_{3}=\mathrm{x}_{1}{ }^{\mathrm{F}}-\mathrm{SZB}_{X}\left(\mathrm{x}_{1}\right) \geqq 0
$$

and for $\left(x_{2}, z_{2}\right)$, the travel lengths are

$$
\begin{gathered}
\mathrm{P}_{1}=\mathrm{z}_{2}-\mathrm{SZB}_{Z}\left(\mathrm{x}_{2}\right) \\
\mathrm{P}_{2}=\frac{\pi}{2} \cdot \mathrm{R}\left(\mathrm{x}_{2}\right) \\
\mathrm{P}_{3}=\mathrm{x}_{2}{ }^{\mathrm{F}}-\operatorname{SZB}_{X}\left(\mathrm{x}_{2}\right) \geqq 0
\end{gathered}
$$

They have to travel the same distances, i.e. $P_{1}+P_{2}+P_{3}$ should be the same. Thus,

$$
z_{1}-\operatorname{SZB}\left(x_{1}\right)+\frac{\pi}{2} \cdot \mathrm{R}\left(x_{1}\right)+x_{1}^{F}-\operatorname{SZB}\left(x_{1}\right)=z_{2}-\operatorname{SZB}\left(x_{2}\right)+\frac{\pi}{2} \cdot \mathrm{R}\left(x_{2}\right)+x_{2}{ }^{F}-\operatorname{SZB}\left(x_{2}\right)
$$

or

$$
z_{1}-2 \cdot \operatorname{SZB}\left(x_{1}\right)+\frac{\pi}{2} \cdot \mathrm{R}\left(x_{1}\right)+x_{1}^{F}=z_{2}-2 \cdot \operatorname{SZB}\left(x_{2}\right)+\frac{\pi}{2} \cdot \mathrm{R}\left(x_{2}\right)+x_{2}{ }^{F}
$$

Rearrange this equation, we have

$x_{2}{ }^{F}-x_{1}{ }^{F}=\left(z_{1}-z_{2}\right)+2 \cdot\left[\operatorname{SZB}\left(x_{2}\right)-\operatorname{SZB}\left(x_{1}\right)\right]+\frac{\pi}{2} \cdot\left[\mathrm{R}\left(x_{1}\right)-\mathrm{R}\left(x_{2}\right)\right]=\left(z_{1}-z_{2}\right)+2 \cdot$

$\left(\frac{W+I-O}{W}\right)\left(x_{2}-x_{1}\right)+\frac{\pi}{2} \cdot\left(\frac{I-O}{W}\right)\left(x_{1}-x_{2}\right)=\left[2 \cdot\left(\frac{W+I-O}{W}\right)-\frac{\pi}{2} \cdot\left(\frac{I-O}{W}\right)\right]\left(x_{2}-x_{1}\right)-\left(z_{2}-z_{1}\right)=$

$\left[2 \cdot\left(1+\frac{I-O}{W}\right)-\frac{\pi}{2} \cdot\left(\frac{I-O}{W}\right)\right]\left(x_{2}-x_{1}\right)-\left(z_{2}-z_{1}\right)$

and

$$
z_{2}^{F}-z_{1}^{F}=x_{2}-x_{1}
$$

With equations (19) and (20), a straight line connecting $\left(x_{1}, z_{1}\right)$ and $\left(x_{2}, z_{2}\right)$ in the entrance channel can be converted to a straight line connecting $\left(x_{1}{ }^{F}, z_{1}{ }^{F}\right)$ and $\left(x_{2}{ }^{F}, z_{2}{ }^{F}\right)$ in the exit channel. The changes in the orientation and the length of the original line can be obtained and will be used in the following analysis. 
In the case illustrated in Fig. 8, a circular element $A B C D$ in the entrance channel is deformed to become $\mathrm{A}^{\prime} \mathrm{B}^{\prime} \mathrm{C}^{\prime} \mathrm{D}$ ' in the exit channel after ECAP. The two perpendicular lines of the same lengths, $\mathrm{AC}$ and $\mathrm{BD}$, are transformed into $\mathrm{A}^{\prime} \mathrm{C}^{\prime}$ and $\mathrm{B}^{\prime} \mathrm{D}^{\prime}$, respectively, with the former lengthened along the maximum principal strain direction and the latter shortened along the minimum principal strain direction. By comparing the elements before and after ECAP, it is seen that the diameter lines located in the white zone are all elongated whereas those in the dark grey zone shortened, with no length change for the two boundary lines. It is also obvious that the change in length is accompanied by a rotation for each line. Using equations (19) and (20), the lengthening ratio $\left(\mathrm{L}_{\mathrm{f}} / \mathrm{L}_{\mathrm{o}}\right.$ where $\mathrm{L}_{\mathrm{f}}$ and $\mathrm{L}_{\mathrm{o}}$ are lengths after and before ECAP, respectively) and rotation angle (counter-clockwise, i.e. $\theta^{\prime}-\theta$ in Fig. 1) as a function of the orientation before ECAP measured as the angle from the exit direction ( $\theta$ in Fig. 1) are plotted in Figs. 9 and 10, respectively, for three die configurations. When the inner and outer radii are equal, the effect is equivalent to that of an ideal, square cornered die with $\mathrm{I}=\mathrm{O}=0$ (the actual radius value does not change the outcome). The maximum lengthening ratio of 2.4 is achieved at $\theta=157.5^{\circ}$ with a $45^{\circ}$ rotation, leading to a final orientation of $\theta^{\prime}=157.5+45=202.5^{\circ}$ (equivalent to $22.5^{\circ}$ ), i.e. the maximum principal strain direction predicted $[16,22]$. For the experimental die used in the present investigation $(\mathrm{I}=5 \mathrm{~mm}$, and $\mathrm{O}=3 \mathrm{~mm}$ ), the larger inner radius increases the maximum lengthening ratio to 2.5 and shifts the maximum principal strain direction to $21.8^{\circ}$. On the other hand, in the case of a larger outer radius $(\mathrm{I}=3 \mathrm{~mm}, \mathrm{O}=5 \mathrm{~mm}$ ), the maximum lengthening ratio is reduced to 2.3 and the maximum principal strain direction is shifted to $23.2^{\circ}$. Therefore, by having a larger inner radius, the maximum principal strain is increased and oriented closer to the exit direction. On the other hand, for $\mathrm{I}=\mathrm{O}$, the line experiencing the most shortening $\left(\mathrm{L}_{\mathrm{f}} / \mathrm{L}_{\mathrm{o}}=0.42\right)$ would have $\theta=67.5^{\circ}$, which rotates by $45^{\circ}$ to orient at $\theta^{\prime}=112.5^{\circ}$ in the exit channel (i.e. perpendicular to the maximum principal strain direction at $22.5^{\circ}$ ). The effect of different $\mathrm{I}$ and $\mathrm{O}$ combinations on shortening is not as significant as on lengthening. It should be noted that in the case of $\mathrm{I}>\mathrm{O}$, a small fraction of the 
lines would undergo rotation in the opposite direction (i.e. clockwise) when the rotation angle becomes negative around $\theta=45^{\circ}$. This reverse rotation pushes a greater number of orientations towards the lengthening region, resulting in a smaller shortening region $\left(46.3^{\circ}<\theta<90^{\circ}\right)$ compared to that for $\mathrm{I}=\mathrm{O}\left(45^{\circ}<\theta<90^{\circ}\right)$ and that for $\mathrm{I}<\mathrm{O}$ cases $\left(43.6^{\circ}<\theta<90^{\circ}\right)$.

\subsection{Transformation of the lamellar $\kappa_{I I I}$ phase}

It is clear from Fig. 3 that the transformation of the $\kappa_{\text {III }}$ lamellae during ECAP is orientation dependent, and this can be analysed by using the model developed in 4.1 . The fragmented $\kappa_{\text {III }}$ lamellae after ECAP deformation tended to align close to $\theta^{\prime}=22^{\circ}$ (Fig. 3a), i.e. in the direction of the maximum principal strain and the maximum lengthening ratio. The process of fragmentation is illustrated in Fig. 11. When the $\kappa_{\text {III }}$ laths are stretched along the lamellar plane (Fig. 11a), the brittle $\kappa_{\text {III }}$ phase simply fractures as it cannot accommodate the tensile strain (Fig. 11b) [25]. Such a phenomena is consistent with the breaking of directionally grown lamellae under tension [26]. Combined with the contraction perpendicular to the lamellae, the fragments are separated and the lamellar spacing is reduced (Fig. 11c). If a random distribution of lamellar orientations is assumed in the as-received material, approximately $75 \%$ of the lamellae would be lengthened (Fig. 9), and this explains a predominantly fragmented $\kappa_{\text {III }}$ lamellar structure after one pass. In contrast, many lamellae perpendicular to this maximum lengthening direction (i.e. the direction of the minimum principal strain and the smallest lengthening ratio) are seen to be buckled (Fig. 3b). This process is schematically shown in Fig. 12. As the lamellae are compressed (Fig. 12a), the thin laths of $\kappa_{\text {III }}$ would buckle and fold, drastically reducing their apparent length (Fig. 12b). Such behaviour is also observed in directionally grown lamellae under uniaxial compression [27, 28]. The buckling of reinforcing fibres under compression was studied experimentally by Lager and June [29], built on the earlier works by Rosen [30] and Sadowsky [31] who modelled the problem as a set of twodimensional plates akin to the lamellar structures here. Lager and June verified two modes of 
buckling depending on the fibre volume fraction: out-of-phase buckling at low volume fractions $\left(\mathrm{v}_{\mathrm{f}}\right.$ $<10 \%)$ and in-phase or 'shear' buckling at higher volume fractions. The small lamellar spacing means a high volume fraction, making in-phase buckling the dominant mode, as observed in Fig. $3 \mathrm{~b}$ and Fig. 4b. A greater compressive stress is required for buckling as the lamellar spacing is decreased, and this explains the varying resistance in lamellar colonies with different lamellar spacings.

The buckling effect discussed above not only allows the lamellae to accommodate the contraction, but also leads to spheroidisation of the $\kappa_{\text {III }}$ phase. As flat surfaces are intrinsically more stable than the curved ones [32], the buckling of lamellae serves to increase chemical potential at the location of curvature. Therefore, the combined effect of elevated temperature, dislocation activity and high curvature may provide sufficient driving force to initiate spheroidisation (Fig. 12c). Evidence of this transformation can be seen in Fig. $4 \mathrm{~b}$ where spheroids (arrow 2) larger than the $\kappa_{\mathrm{IV}}$ precipitates are seen to develop from the buckled lamellae (arrow 1). However, most of the buckled lamellae remain unbroken after one pass of ECAP. In comparison, fragmentation is much more effective in refining the lamellar $\kappa_{\text {III }}$ since no colony undergoing elongation is left intact.

\subsection{Effects of ECAP routes on lamellar transformation}

As the evolution of the lamellar $\kappa_{\text {III }}$ depends strongly on the initial orientations before passing through the shear zone, the route of ECAP plays an important role as it determines the initial orientations for the next pass. The deformation indicators used in the geometric model for the first pass (Fig. 8) can be applied to subsequent passes to investigate the effects of various routes on the $\kappa_{\text {III }}$ transformation. In Fig. 13, the ellipses formed after the first pass (with the already lengthened and shortened regions marked) are replaced in the entrance channels ready for the second pass via route $\mathrm{A}$ and route $\mathrm{C}$, respectively. The ellipse for route $\mathrm{A}$ and circle for route $\mathrm{C}$ in 
the exit channels represent the elements after the second pass. The circular indicators in the entrance channels are placed to identify the lengthening and shortening orientations for the second pass.

\subsubsection{Route $C$}

Consider the geometrically simple case of route $\mathrm{C}$ first. Thanks to the $180^{\circ}$ rotation between passes, all the orientations that have been stretched in the first pass would be compressed in the second pass and vice versa (Fig. 13), in agreement with the fact that the second pass reverses the shear strain in the first pass [16] and as evidenced by the largely restored microstructure in Fig. 6a. Consequently, route $\mathrm{C}$ is not very efficient in transforming the lamellar $\kappa_{\mathrm{III}}$ and large regions of apparently intact lamellae can still be found after four passes. Moreover, the $\kappa_{\text {III }}$ particles are mostly limited to the vicinity of the original colonies, rather than being more uniformly distributed. However, the lamellar structure is still gradually transformed since some changes cannot be restored, including the fragmentation of the $\kappa_{\mathrm{III}}$ lamellae, the reduction in lamellar spacing and spheroidisation due to buckling. The numerous hairline cracks in the 'reformed' lamellae facilitates accelerated spheroidisation through fault migration [33, 34]. This is aided by the continual reduction in lamellar spacing which decreases the required diffusion distances [32, 35]. Buckling would reorient some section of the lamellae (in particular the ends) into the fragmentation directions, leading to their fracture in the next pass, as indicated by the abrupt change from intact to fragmented lamellae (arrow 4 in Fig. 6b). The restoration of the buckled lamellae is also not perfect as implied by the waviness of the otherwise straight lamellae (arrow 2 in Fig. 6b) which leads to the bands of fragments (arrow 3 in Fig. 6e) and the coarse breakages (arrow 4) on the fourth pass, as segments of the bent lamellae may be oriented towards the lengthening region and be fractured. Overall, the various "imperfect restorations" discussed above allow route $\mathrm{C}$ to gradually, although not efficiently, break down the lamellar $\kappa_{\text {III. }}$

\subsubsection{Route A}


Route $\mathrm{A}$ is very different from route $\mathrm{C}$ as all previously elongated orientations would continue to be stretched on the second pass (Fig. 13). This is reflected in the development of a layered structure with increasing number of passes (Fig. 4): both the lamellar colonies and primary $\alpha$ grains have been stretched into long bands. On the other hand, as indicated by Fig. 13, more than half of the previously compressed directions would undergo stretching in the second pass. This would facilitate a more efficient refinement of lamellae since most of them would eventually rotate to the fragmentation orientations.

The contribution of lamellar buckling to fragmentation on subsequent passes, as discussed above with route $\mathrm{C}$, is also apparent in route $\mathrm{A}$ with abrupt changes from highly fragmented to intact lamellae throughout the microstructure (arrow 3 in Fig. 4a). On the other hand, the increase in lamellar spacing (arrow 2 in Fig. 4a) in the buckled lamellae may enhance further distortion of the lamellae. As more widely spaced lamellae are easier to deform [29], colonies which continue to contract are likely to become more warped than previously. The resulting increase in lath curvature would bring about greater spheroidisation, accelerating the breaking down of the compressed lamellae. In summary, route A can efficiently transform the lamellar $\kappa_{\text {III }}$ to particles of sizes similar to those of the $\kappa_{\mathrm{IV}}$ precipitates and distribute the various phases to create a highly homogeneous microstructure.

\subsubsection{Routes $B_{A}$ and $B_{C}$}

In route $\mathrm{A}$, the orientations of the streams of fragmented $\kappa_{\text {III }}$ closely follow those predicted by the geometric model, i.e. starting at $\sim 21.8^{\circ}$ after the first pass, reduced to $\sim 12.3^{\circ}$ after the second pass and then decreasing with each subsequent pass, as described above. In contrast, after the second pass via the $\mathrm{B}$ routes (i.e. with a rotation by $90^{\circ}$ ), the streams (although not as obvious as in route A) of $\kappa_{\text {III }}$ fragments appear to orient at $\sim 25^{\circ}$ to the exit direction (Fig. 5a), greater than that after the first pass $\left(\sim 20.8^{\circ}\right)$. Such an apparently different behaviour can be explained by taking the 
rotation into consideration in the geometric model, as shown in Fig. 14. The shear pattern observed on the $x-z$ plane would be the same along the $y$ direction in any particular pass of ECAP. The three dimensional morphology of the fragmented lamellae after the first pass would look like that depicted in Fig. 14a, with an inclination angle of $\sim 20.8^{\circ}$ to the $x$ axis but no fracture along the $y$ direction. When rotated by $90^{\circ}$ and reinserted into the entrance channel, the lamellae would be oriented at $\theta=0^{\circ}$ in the $x-z$ section and be reoriented to $\theta^{\prime} \approx 26.5^{\circ}$ (Fig. 10) after the second pass, as shown in Fig. 14b and consistent with observation in Fig. 5a. From the third pass, route $\mathrm{B}_{\mathrm{A}}$ and $\mathrm{B}_{\mathrm{C}}$ lead to different outcomes, as shown in Figs. $14 \mathrm{c}$ and $14 \mathrm{~d}$ for $\mathrm{B}_{\mathrm{A}}$ and Figs. $14 \mathrm{e}$ and $14 \mathrm{f}$ for $\mathrm{B}_{\mathrm{C}}$, respectively. The angle predicted, $\theta^{\prime} \approx 13.4^{\circ}$ (Fig. $14 \mathrm{~d}$ ) after fourth pass via $\mathrm{B}_{\mathrm{A}}$, is similar to the prevailing angle of $\sim 17^{\circ}$ seen in Fig. $5 \mathrm{~b}$. On the other hand, although the model predicts a vertical orientation after the fourth pass via $\mathrm{B}_{\mathrm{C}}$ (Fig. 14f), the actual orientation is close to $\sim 60^{\circ}$ (Fig. $5 \mathrm{c}$ ). This discrepancy will be discussed in the following section.

\subsubsection{Experimental variation from Geometric model}

Thus far, only the ideal ECAP conditions have been considered. We now discuss some of the deviations during the real experiments which have considerable effects on the resulting microstructure. For easier insertion and lubrication, the cross-section of the specimen $(8 \times 8 \mathrm{~mm})$ was made slightly smaller than the channel cross-section $(9 \times 9 \mathrm{~mm})$. This resulted in a slight compression of the specimen before it entered the shear zone and a noticeable effect on the initial lamellar orientations, as illustrated in Fig. 15: the diagonal line in Fig. 15a before compression was rotated to the new position in Fig. 15b after compression. This effect was significant in some cases, as exemplified by the microstructures resulting from route $\mathrm{B}_{\mathrm{A}}$ and $\mathrm{B}_{\mathrm{C}}$. For $\mathrm{B}_{\mathrm{A}}$, the predicted orientation of the fragmented streams is $\theta^{\prime}=13.4^{\circ}$ after 4 passes without the compression correction and $\theta^{\prime}=15.5^{\circ}$ after the correction, compared to $\theta^{\prime} \approx 17^{\circ}$ observed (Fig. 5b). For $\mathrm{B}_{\mathrm{C}}$, the predicted orientation of the fragmented streams is $\theta^{\prime}=90^{\circ}$ after 4 passes without the compression correction 
and $\theta^{\prime}=59.5^{\circ}$ after the correction, compared to $\theta^{\prime} \approx 60^{\circ}$ observed (Fig. 5c). Therefore, the differences between the ideally predicted angles and those observed are largely due to the compression effect. The implication of this result is that deformation prior to ECAP may be exploited to purposely shift lamellae from the shortening to the lengthening orientations with a view to maximising fragmentation and refinement of the lamellae, if the benefit gained is high enough to outweigh the material loss due to machining between passes.

\subsection{Microstructural implications}

The difference between routes A (without redundant strain) and $\mathrm{C}$ (with redundant strain) is unambiguous, and route A is considerably more effective in breaking down the lamellar structure, as discussed above. In both cases, however, the deformation is limited to the $x-z$ plane (plane strain deformation on the same plane on all the passes). On the other hand, the $90^{\circ}$ rotation between passes in the $\mathrm{B}$ routes introduces deformation in the direction perpendicular to the $\mathrm{x}-\mathrm{Z}$ plane and thus allows lamellar refinement in all three dimensions. This is responsible for the greater occurrence of spheroidisation on the second pass in the plates experiencing buckling (Fig. 5a), compared to the situations in routes A (Fig. 4b) and C (Fig. 6b). The process of spheroidisation in routes $\mathrm{B}$ is illustrated in Fig. 16. On the first pass, the contraction of the lamellae causes them to buckle into waved shape (Fig. 16a). After rotation by $90^{\circ}$, the second pass compresses the lamellae in the perpendicular direction, creating three-dimensionally undulating surfaces (Fig. 16b). The peaks and troughs generate many more potential sites for the onset of spheroidisation than those in routes $\mathrm{A}$ and $\mathrm{C}$, leading to faster breakdown of the lamellae (Fig 16c). The effect of the $90^{\circ}$ rotation is also significant for the lamellae undergoing stretching and fragmentation. As seen in Fig. 14a, the long strips which remain unbroken in the $y$ direction after the first pass would either be stretched to fragment or be compressed to buckle and spheroidise on subsequent passes. Together with enhanced spheroidisation, this cross-cutting effect leads to a complete breakdown of the lamellar structure in three dimensions, leading to routes B to be more efficient than route A in breaking 
down the lamellar structure. It is expected that the use of either route A or the B routes would eliminate the need for further heat treatment used in [10] and [12] in which route $\mathrm{C}$ was employed.

\subsection{Effects of different lamellar configurations}

The model developed here and related analyses are applicable to ECAP of alloys with a duplex microstructure of lamellar colonies among softer matrix grains, including low [13] and medium carbon steels [15] where the duplex structure of the pearlite colonies and ferrite grains closely resemble that of the lamellar $\kappa_{\text {III }}$ colonies and primary $\alpha$ grains of NAB in the present investigation. The softer matrix grains surrounding the lamellae are able to deform and thus allow the rotation and deformation of the lamellar colonies. In contrast, in alloys with a microstructure consisting of completely or dominantly eutectic colonies such as $\mathrm{Cu}-33$ wt.\% $\mathrm{Ag}$ [11] and high carbon steel [12], the deformation (lengthening or shortening) and rotation of the lamellar colonies are restricted by the surrounding ones, resulting in the cutting of lamellae through shear in order to accommodate the geometric distortion during ECAP. As in the present work, the application of route $\mathrm{B}_{\mathrm{C}}$ caused cross cutting of the lamellae and the efficient elimination of the remaining lamellar structure through spheroidisation. Moreover, no lamellar fragmentation or buckling was observed in ECAP of a forged $\mathrm{Cu}-8$ wt.\% Ag eutectic alloy with a duplex structure despite using all the four different routes [19]. This is because the non-matrix lamellae in the colonies were the softer and ductile Ag phase (rather than the hard and brittle cementite in the steels or $\kappa_{I I I}$ in NAB), which stretched into fine fibres (rather than fragmentation) when using route $\mathrm{A}$ or $\mathrm{B}_{\mathrm{A}}$ and formed a globular morphology when using route $\mathrm{C}$ or $\mathrm{B}_{\mathrm{C}}$. This globular form is a likely result of direct compression of the eutectoid, rather than the buckling effect seen in this study.

\section{Conclusions}

(1) Cast $\mathrm{NAB}$ was processed by ECAP for up to 4 passes via routes $\mathrm{A}, \mathrm{B}_{\mathrm{A}}$, $\mathrm{B}_{\mathrm{C}}$ and $\mathrm{C}$, respectively. Routes $\mathrm{A}, \mathrm{B}_{\mathrm{A}}$ and $\mathrm{B}_{\mathrm{C}}$ were all highly effective in transforming the lamellar $\kappa_{\mathrm{III}}$ 
into a mixture of fine fragments and spheroidised particles. In contrast, route $\mathrm{C}$ was unable to completely remove the lamellar $\kappa_{\text {III }}$ even after four passes.

(2) A geometric model is established to enable systematic and quantitative analysis of the transformation of the lamellae. The changes in the lengths and orientations of the lamellae can be calculated and are dependent on their initial orientations before ECAP. Aside from several special orientations, the lamellae are either lengthened or shortened, and rotated by the shear deformation.

(3) In particular, after the first pass the majority of the lamellae would be stretched in the directions near the principal strain direction, leading to fragmentation, and some be compressed in the perpendicular directions, resulting in buckling and spheroidisation at the locations of high curvature. In route A, all the lamellae would eventually be rotated to directions of stretching and fragmented whereas in route $\mathrm{C}$, partial restoration on even numbered passes makes it less efficient in breaking down the lamellar structure. In routes B, the 90 degree rotation allows fragmentation of the stretched lamellae to occur in perpendicular directions and the compressed lamellae to form undulated surfaces highly susceptible to spheroidisation. Consequently, routes B lead to the most efficient transformation of the lamellar structure.

(4) Compression of the ECAP sample (due to its smaller cross section than the channel cross section) prior to its passing through the shear zone may alter the original lamellar orientations for each pass and need to be taken into consideration when using the geometric model.

(5) The model applies generally to the transformation by ECAP of an initially duplex microstructure consisting of harder and brittle lamellae and a softer matrix phase, including NAB investigated here and low and medium carbon steels. In the case of a fully lamellar 
structure or a duplex structure with softer and ductile lamellae in a harder matrix phase, the movement of the lamellae would be restricted, leading to different observations of the lamellar transformation.

\section{Acknowledgements}

The authors would like to acknowledge the support of the Defence Materials Technology Centre (DMTC). The DMTC was established and is supported under the Australian Government's Defence Future Capability Technology Centres Programme. 


\section{References}

[1] E.A. Culpan, and G. Rose: J. Mater. Sci., 1979, vol. 14, pp. 160-66.

[2] E.A. Culpan: J. Mater. Sci., 1978, vol. 13, pp. 1647-57.

[3] J.A. Wharton, R.C. Barik, G. Kear, R.J.K. Wood, K.R. Stokes, and F.C. Walsh: Corros. Sci., 2005, vol. 47, pp. 3336-67.

[4] B.E. Curry, S.H. Woods: J. Phys. Chem., 1907, vol. 11, pp. 461-491.

[5] M. Cook, W. Fentiman, and E. Davis: J. Inst. Met., 1951, vol. 80, pp. 419-29.

[6] F. Hasan, G.W. Lorimer, and N. Ridley: Met. Sci., 1983, vol. 17, pp. 289-96.

[7] F. Hasan, A. Jahanafrooz, G.W. Lorimer, and N. Ridley, Metall. Mater. Trans. A, 1982, vol. 13, pp. 1337-1345.

[8] A. Al-Hashem, and W. Riad: Mater. Charact., 2002, vol. 48, pp. 37-41.

[9] D.R. Ni, B.L. Xiao, Z.Y. Ma, Y.X. Qiao, and Y.G. Zheng: Corros. Sci., 2010, vol. 52, pp. 1610-17.

[10] J.A. Wharton, and K.R. Stokes: Electrochim. Acta, 2008, vol. 53, pp. 2463-73.

[11] J. Wang, S.B. Kang, and H.W. Kim: Mater. Sci. Eng. A, 2004, vol. 383, pp. 356-61.

[12] T. He, Y. Xiong, F. Ren, Z. Guo, and A.A.Volinsky: Mater. Sci. Eng. A, 2012, vol. 535, pp. 306-10.

[13] D.H. Shin, B.C. Kim, K.T. Park, and W.Y. Choo: Acta Mater., 2000, vol. 48, pp. 3245-52.

[14] D.H. Shin, S.Y. Han, K.T. Park, Y.S. Kim, and Y.N. Paik: Mater. Trans., 2003, vol. 44, pp. 1630-35. 
[15] L.W. Ma, and K. Xia: Kovove Mater., 2011, vol. 49, pp. 23-27.

[16] R.Z. Valiev, and T.G. Langdon: Prog. Mater. Sci., 2006, vol. 51, pp. 881-981.

[17] K.D. Ralston, N. Birbilis, and C.H.J. Davies: Scr. Mater., 2010, vol.63, pp. 1201-04.

[18] M. Haouaoui, I. Karaman, H.J. Maier: Acta Mater., 2006, vol. 54, pp. 5477-5488.

[19] Y.Z. Tian, Q.Q. Duan, H.J. Yang, H.F. Zou, G. Yang, S.D. Wu, and Z.F. Zhang: Metall. Mater. Trans. A, 2010, vol. 41, pp. 2290-303.

[20] C.J. Barr, D.T. McDonald, and K. Xia: J. Mater. Sci., 2013, vol. 48, pp. 4749-4757.

[21] D.T. McDonald, C.J. Barr, and K. Xia: Metall. Mater. Trans. A, 2013, vol. 51, pp. 5556-66.

[22] K. Xia, and J. Wang: Metall. Mater. Trans. A, 2001, vol. 32, pp. 2639-47.

[23] W.Z. Han, Z.F. Zhang, S.D. Wu, and S.X. Li: Phil. Mag. Lett., 2007, vol. 87, pp. 735-41.

[24] W.Z. Han, Z.F. Zhang, S.D. Wu, and S.X. Li: Mater. Sci. Eng. A, 2008, vol. 476, pp. 224-29.

[25] S.J. Jeon, and H.C. Lee: Mater. Sci. Eng. A, 1992, vol. 153, pp. 392-97.

[26] M. Dupeux, and F. Durand: Metall. Trans. A, 1975, vol. 6, pp. 2143-51.

[27] A. Pattnaik, and A .Lawley: Metall. Trans., 1971, vol. 2, pp. 1529-36.

[28] B.J. Shaw: Acta Metall., 1967, vol. 15, pp. 1169-77.

[29] J.R. Lager, and R.R. June: J. Compos. Mater., 1969, vol. 3, pp. 48-56.

[30] B.W. Rosen: Mechanics of Composite Strengthening, Fiber Composite Materials, ASM Metals Park OH 1965, 37.

[31] M.A. Sadowsky, S.L. Pu, and M.A. Hussain: J. Appl. Mech., 1967, vol. 34, pp. 1011-1016. 
[32] P.W. Voorhees: J. Stat. Phys., 1985, vol. 38, pp. 232-252

[33] J.C. Kampe, T.H. Courtney, and Y. Leng: Acta Metall., 1989, vol. 37, pp. 1735-56.

[34] T.H. Courtney, and J.C. Kampe: Acta Metall., 1989, vol. 37, pp. 1747-58.

[35] D.R.H. Jones: J Mater. Sci., 1974, vol. 9, pp. 989-92. 


\section{Figure Captions}

Fig. 1 Schematic of the ECAP setup, with angles $\theta$ and $\theta^{\prime}$ measuring the lamellar orientations before and after ECAP. The shear zone (S.Z.) is defined by the inner $(5 \mathrm{~mm})$ and outer $(3$ $\mathrm{mm}$ ) radii used. The exit direction is horizontal and pointing to the right (x-direction).

Fig. 2 As-received microstructure of NAB showing the various types of the $\kappa$ phases $\left(\kappa_{\mathrm{I}}\right.$ is rarely seen).

Fig. 3 Microstructures after ECAP for one pass showing (a) highly fragmented $\kappa_{\text {III }}$ lamellae aligned at $\theta^{\prime} \approx 22^{\circ}$ to the exit direction, (b) buckled lamellae perpendicular to $\theta^{\prime} \approx 22^{\circ}$, and (c) and (d) largely undeformed lamellae at $\theta^{\prime} \approx 45^{\circ}$ and $\theta^{\prime} \approx 0^{\circ}$, respectively.

Fig. 4 Microstructures after ECAP via route A for (a) 2 passes showing mostly further elongated lamellar colonies and $\alpha$ grains oriented at $\theta^{\prime} \approx 14^{\circ}$, (b) 2 passes showing occasionally further buckled and spaced $\kappa_{\mathrm{III}}$ lamellae, and (c) 4 passes showing completely transformed $\kappa_{\text {III }}$.

Fig. 5 Microstructures after ECAP for (a) 2 passes via route B showing fragmented $\kappa_{\text {III }}$ streams oriented at $\theta^{\prime} \approx 25^{\circ}$ and some buckled $\kappa_{\text {III }}$ plates, and (b) 4 passes via route $\mathrm{B}_{\mathrm{A}}$ and (c) 4 passes via route $\mathrm{B}_{\mathrm{C}}$, showing completely fragmented/spheroidised $\kappa_{\mathrm{III}}$ structures with layers oriented at $\theta^{\prime} \approx 17^{\circ}$ and $\theta^{\prime} \approx 60^{\circ}$, respectively.

Fig. 6 Microstructures after ECAP via route C for (a) 2 passes showing 'reformed' lamellae with cracks (inset), (b) 2 passes showing intact laths (arrow 1), wavy laths (arrow 2) and clusters of spheroidised $\kappa_{\text {III }}$ particles (arrow 3), (c) 3 passes showing finely spheroidised $\kappa_{\text {III }}$ (arrowed), (d) 3 passes showing increasingly warped lamellae, and (e) 4 passes showing an inhomogeneous microstructure compared to the ones after 4 passes via A and $B$ routes. 
Fig. 7 Geometrical setup of the ECAP die used in the model, showing the path of an element at an initial position $\left(x_{0}, z_{0}\right)$ travelling to a final position $\left(x_{o}{ }^{F}, z_{o}{ }^{F}\right)$. W, I and $\mathrm{O}$ are the width, inner and outer radii of the die, respectively; $\mathrm{R}$ is the radius of the path in the shear zone; $\mathrm{SZB}_{\mathrm{z}}$ and $\mathrm{SZB}_{\mathrm{x}}$ are the shear zone boundaries in the entrance and exit channels, respectively.

Fig. 8 A circular element $A B C D$ in the entrance channel is deformed to become $A$ 'B'C'D' in the exit channel, with $\mathrm{AC}$ lengthened to become $\mathrm{A}^{\prime} \mathrm{C}^{\prime}$ in the maximum principal strain direction and $\mathrm{BD}$ shortened to become $\mathrm{B}^{\prime} \mathrm{D}^{\prime}$ in the minimum principal strain direction. The diameter lines in the white zone are lengthened and those in the dark grey zone shortened after ECAP. The grey circle provides a direct comparison before and after ECAP.

Fig. 9 Length change expressed as the ratio of the final length $\left(L_{\mathrm{f}}\right)$ to the initial length $\left(L_{\mathrm{o}}\right)$ versus the orientation before ECAP expressed as the angle measured from the exit direction ( $\theta$ in Fig. 1) for three different die configurations: $\mathrm{I}=\mathrm{O}, \mathrm{I}>\mathrm{O}(\mathrm{I}=5 \mathrm{~mm}$ and $\mathrm{O}$ $=3 \mathrm{~mm}$, the present configuration $)$ and $\mathrm{I}<\mathrm{O}(\mathrm{I}=3 \mathrm{~mm}$ and $\mathrm{O}=5 \mathrm{~mm})$.

Fig. 10 Rotation angle (counter-clockwise, i.e. $\theta^{\prime}-\theta$ in Fig. 1) versus the orientation before $\operatorname{ECAP}(\theta$ in Fig. 1$)$ for three different die configurations: $\mathrm{I}=\mathrm{O}, \mathrm{I}>\mathrm{O}(\mathrm{I}=5 \mathrm{~mm}$ and $\mathrm{O}=$ $3 \mathrm{~mm}$, the present configuration) and $\mathrm{I}<\mathrm{O}(\mathrm{I}=3 \mathrm{~mm}$ and $\mathrm{O}=5 \mathrm{~mm})$.

Fig. 11 Illustrated process of $\kappa_{\text {III }}$ fragmentation upon lengthening: (a) lamellae subjected to tension, (b) cracking of the lamellae under tension and filling of the gap by the matrix $\alpha$ due to compression in the perpendicular direction, and (c) separation of the $\kappa_{\mathrm{III}}$ fragments and reduction in lamellar spacing.

Fig. 12 Illustrated process of $\kappa_{\text {III }}$ buckling upon shortening: (a) lamellae subjected to compression, (b) lamellar buckling and folding to accommodate the shortening, and (c) spheroidisation at places of high curvature. 
Fig. 13 The geometric model applied to the second pass via route A and route C, respectively. The ellipses in the entrance channels represent the elements shaped after the first pass and replaced there for the second pass. The dashed circle in each entrance channel indicates the lengthening and shortening orientations for the second pass (with the same meaning as in Fig. 8). The shapes and patterns in the exit channel represent the cumulative effects of the two passes, with the letters with primes in the exit channels tracing those in the entrance channels.

Fig. 14 Three dimensional morphologies of the fragmented $\kappa_{\text {III }}$ laths (a) after the first pass, (b) before and after the second pass via the B routes, (c) after the third pass via $\mathrm{B}_{\mathrm{A}}$, (d) before and after the fourth pass via $\mathrm{B}_{\mathrm{A}}$, (e) after the third pass via $\mathrm{B}_{\mathrm{C}}$, and (f) before and after the fourth pass via $\mathrm{B}_{\mathrm{C}}$. The $x-z$ and $x-y$ views are sections at a certain $y$ and a certain $z$, respectively.

Fig. 15 The shapes of the ECAP specimen in the entrance channel (a) as-inserted and (b) after compression (before entering the shear zone), illustrating the change of orientation of the diagonal line.

Fig. 16 Illustrated process of spheroidisation for lamellae experiencing contraction and buckling in route B: (a) initial buckling of the lamellae (b) further compression (perpendicular to the first pass) on the second pass causing the formation of undulated surfaces, and (c) spheroidisation of the peaks and troughs leading to a complete breakdown of the lamellae. 


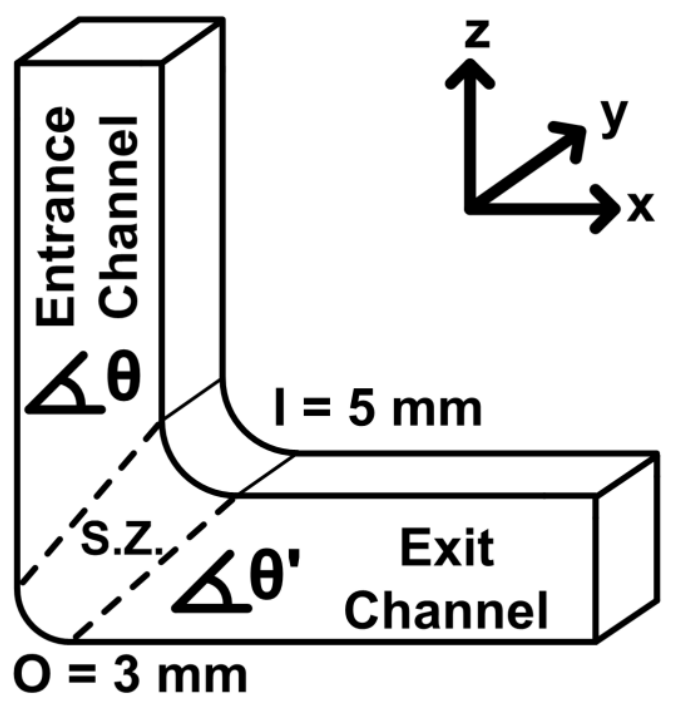

Fig. 1. Schematic of the ECAP setup, with angles $\theta$ and $\theta^{\prime}$ measuring the lamellar orientations before and after ECAP. The shear zone (S.Z.) is defined by the inner ( 5 $\mathrm{mm})$ and outer $(3 \mathrm{~mm})$ radii used. The exit direction is horizontal and pointing to the right ( $\mathrm{x}$-direction).

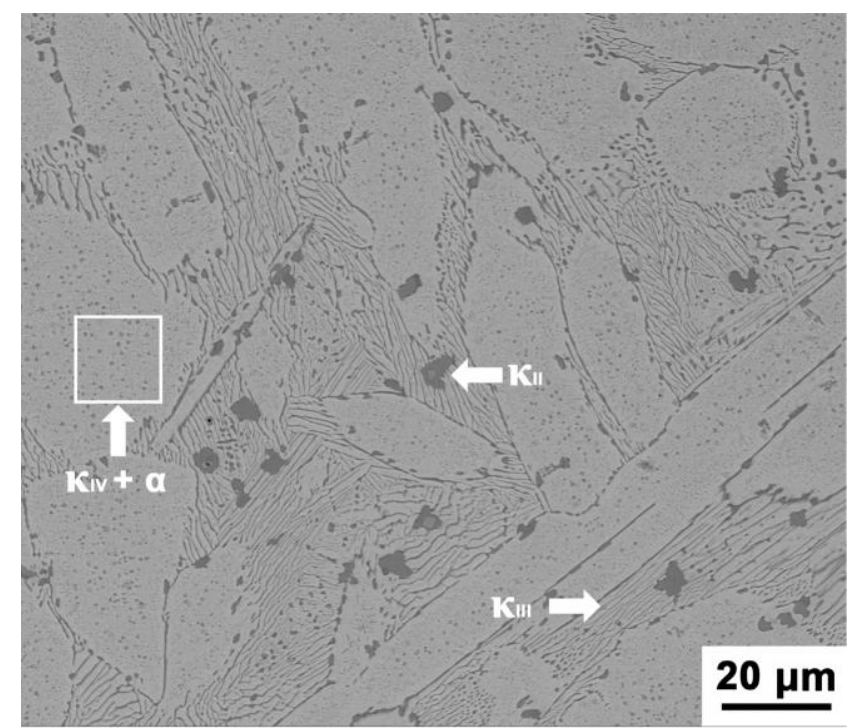

Fig. 2. As-received microstructure of NAB showing the various types of the $\kappa$ phases ( $\mathrm{K}_{\mathrm{I}}$ is rarely seen). 

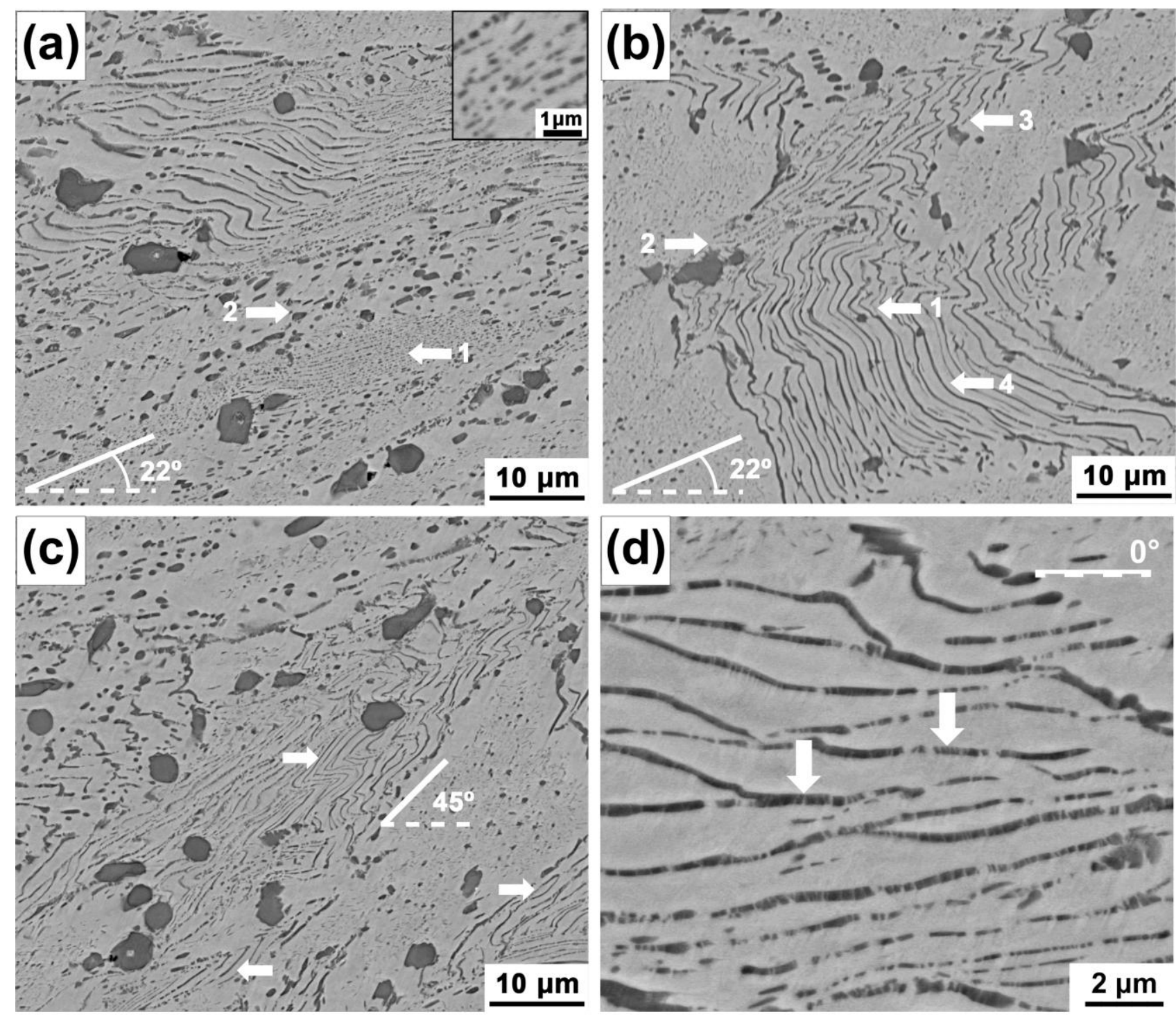

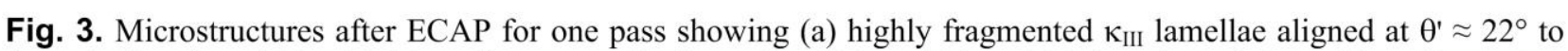
the exit direction, (b) buckled lamellae perpendicular to $\theta^{\prime} \approx 22^{\circ}$, and (c) and (d) largely undeformed lamellae at $\theta^{\prime} \approx$ $45^{\circ}$ and $\theta^{\prime} \approx 0^{\circ}$, respectively. 


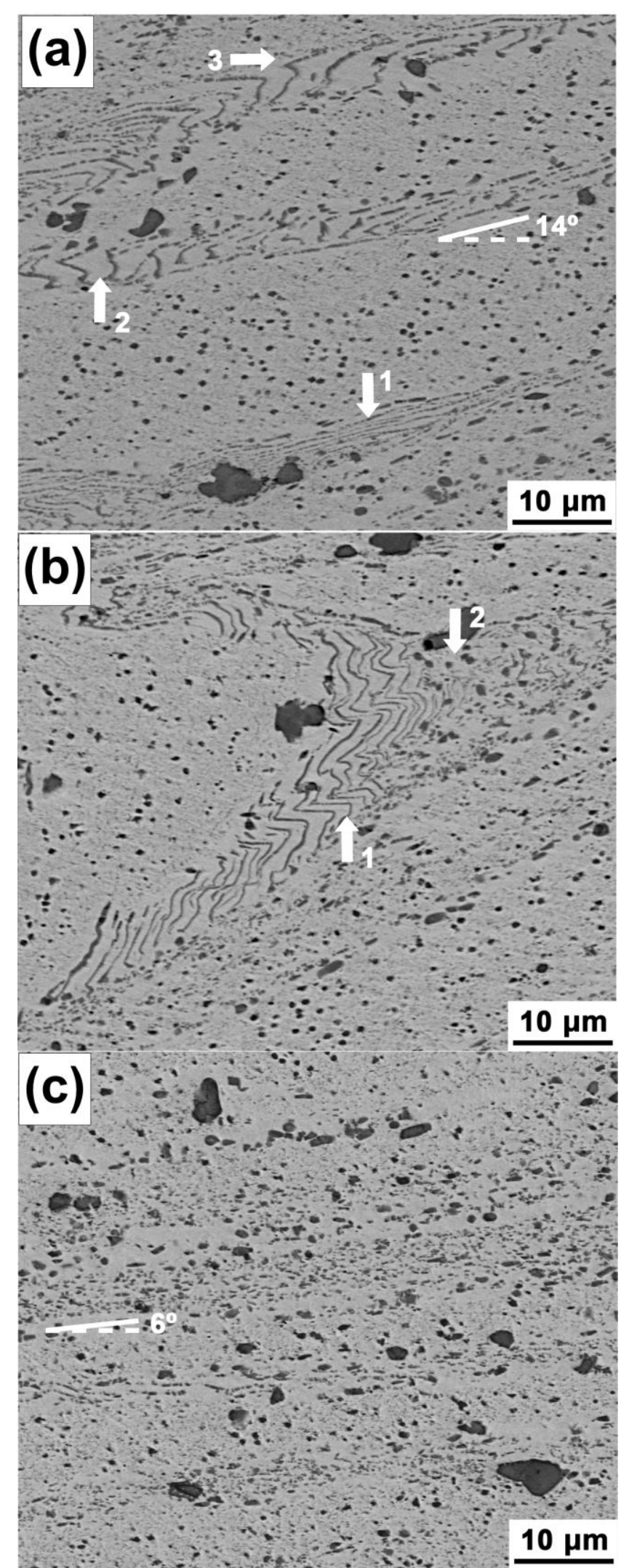

Fig. 4. Microstructures after ECAP via route A for (a) 2 passes showing mostly further elongated lamellar colonies and $\alpha$ grains oriented at $\theta^{\prime} \approx 14^{\circ}$, (b) 2 passes showing occasionally further buckled and spaced $\kappa_{\text {III }}$ lamellae, and (c) 4 passes showing completely transformed $\kappa_{\mathrm{III}}$. 

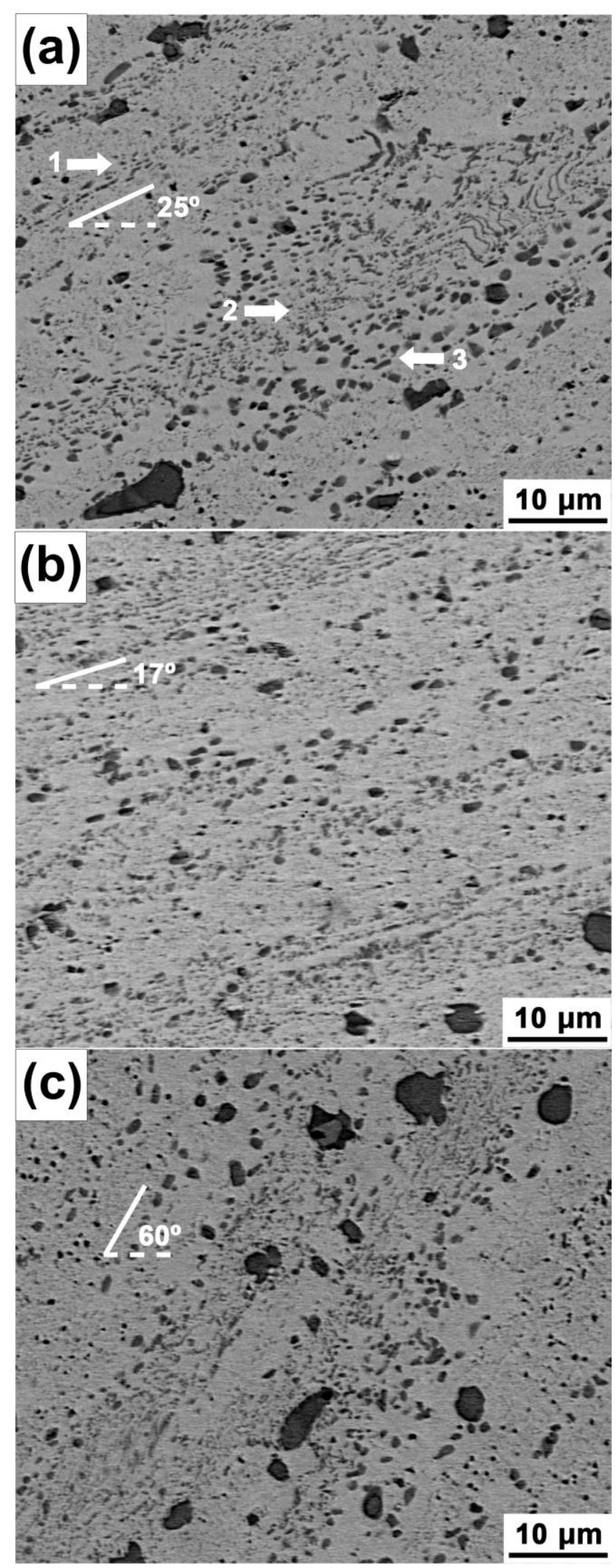

Fig. 5. Microstructures after ECAP for (a) 2 passes via route $B$ showing fragmented $\mathrm{K}_{\mathrm{III}}$ streams oriented at $\theta^{\prime} \approx 25^{\circ}$ and some buckled $\mathrm{K}_{\text {III }}$ plates, and (b) 4 passes via route $\mathrm{B}_{\mathrm{A}}$ and (c) 4 passes via route $\mathrm{B}_{\mathrm{C}}$, showing completely fragmented/spheroidised $\mathrm{K}_{\mathrm{III}}$ structures with layers oriented at $\theta^{\prime} \approx 17^{\circ}$ and $\theta^{\prime} \approx 60^{\circ}$, respectively. 

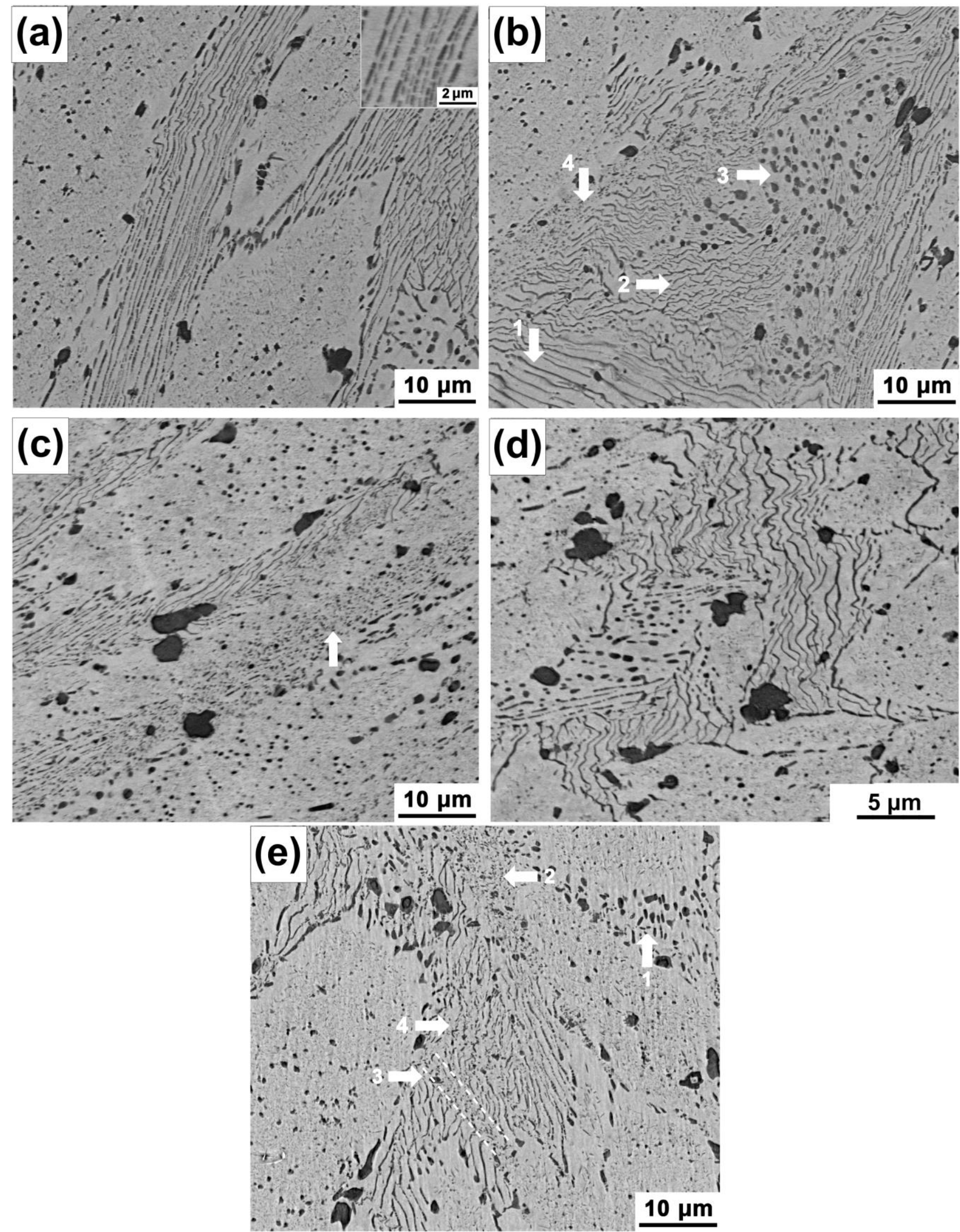

Fig. 6. Microstructures after ECAP via route $C$ for (a) 2 passes showing 'reformed' lamellae with cracks (inset), (b) 2 passes showing intact laths (arrow 1), wavy laths (arrow 2) and clusters of spheroidised $\mathrm{K}_{\mathrm{III}}$ particles (arrow 3), (c) 3 passes showing finely spheroidised $\mathrm{K}_{\mathrm{III}}$ (arrowed), (d) 3 passes showing increasingly warped lamellae, and (e) 4 passes showing an inhomogeneous microstructure compared to the ones after 4 passes via $\mathrm{A}$ and $\mathrm{B}$ routes. 


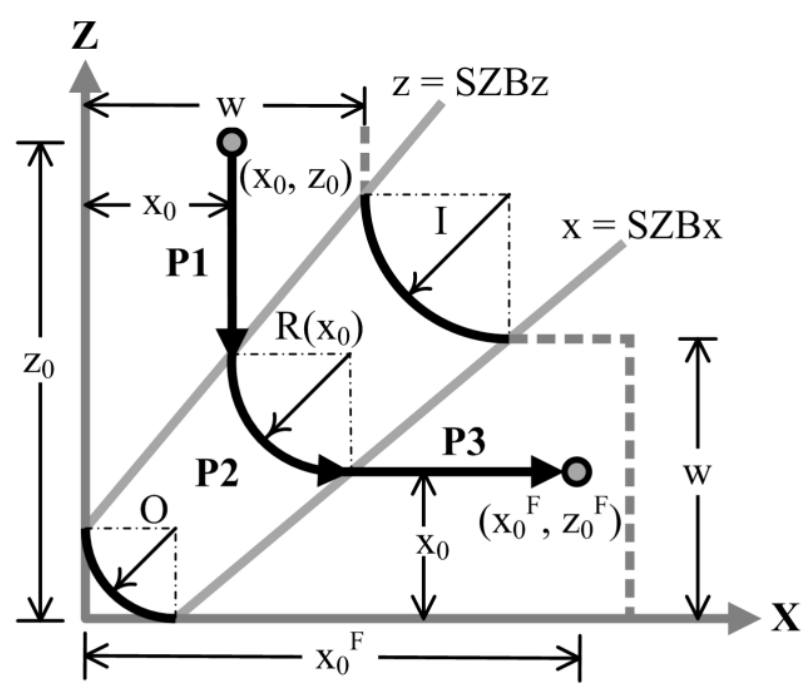

Fig. 7. Geometrical setup of the ECAP die used in the model, showing the path of an element at an initial position $\left(x_{\mathrm{o}}, z_{\mathrm{o}}\right)$ travelling to a final position. $\mathrm{W}, \mathrm{I}$ and $\mathrm{O}$ are the width, inner and outer radii of the die, respectively; $\mathrm{R}$ is the radius of the path in the shear zone; $\mathrm{SZB}_{z}$ and $\mathrm{SZB}_{\mathrm{x}}$ are the shear zone boundaries in the entrance and exit channels, respectively.

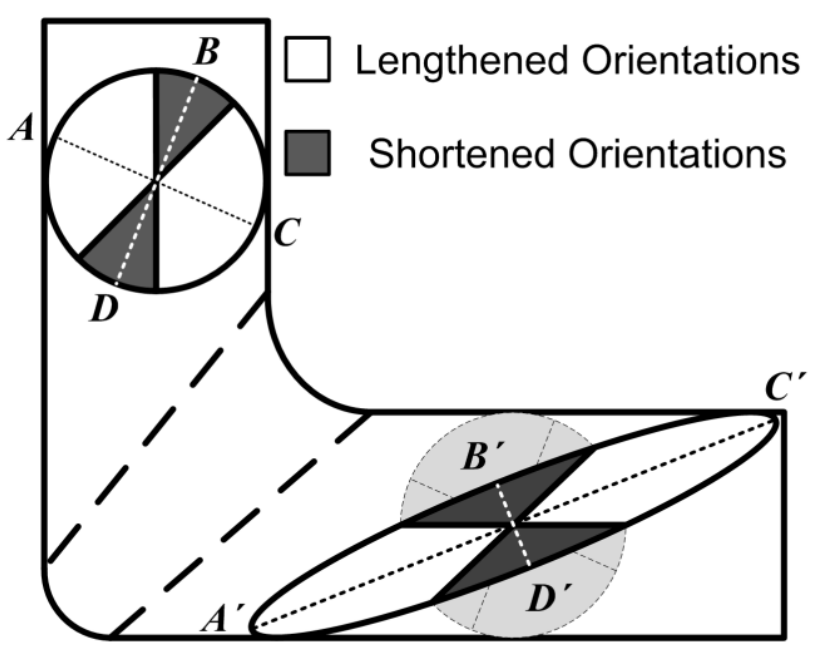

Fig. 8. A circular element $\mathrm{ABCD}$ in the entrance channel is deformed to become $\mathrm{A}^{\prime} \mathrm{B}^{\prime} \mathrm{C}^{\prime} \mathrm{D}^{\prime}$ in the exit channel, with $\mathrm{AC}$ lengthened to become $\mathrm{A}^{\prime} \mathrm{C}^{\prime}$ in the maximum principal strain direction and $\mathrm{BD}$ shortened to become $\mathrm{B}^{\prime} \mathrm{D}^{\prime}$ in the minimum principal strain direction. The diameter lines in the white zone are lengthened and those in the dark grey zone shortened after ECAP. The grey circle provides a direct comparison before and after ECAP. 


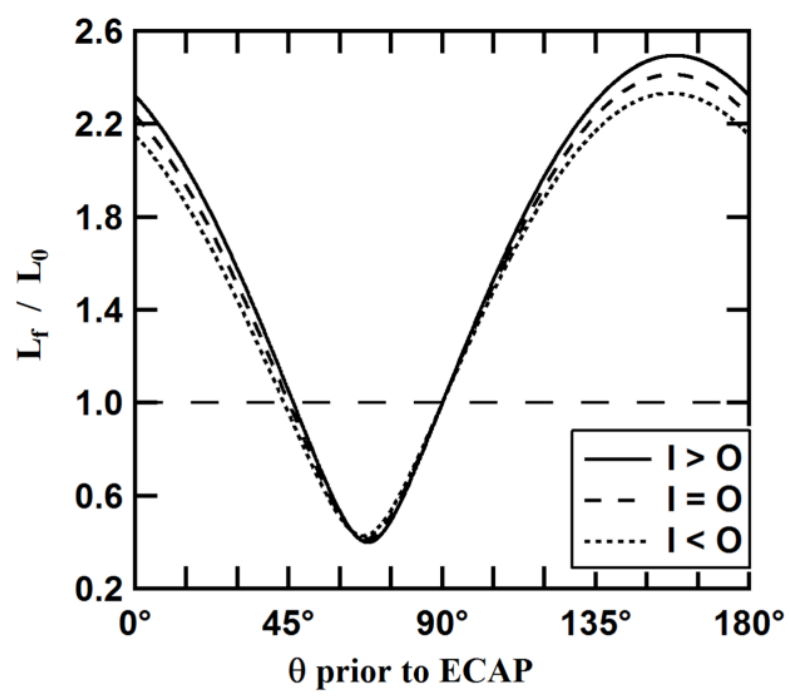

Fig. 9. Length change expressed as the ratio of the final length $\left(L_{\mathrm{f}}\right)$ to the initial length $\left(L_{\mathrm{o}}\right)$ versus the orientation before ECAP expressed as the angle measured from the exit direction ( $\theta$ in Fig. 1) for three different die configurations: $\mathrm{I}=\mathrm{O}, \mathrm{I}>\mathrm{O}(\mathrm{I}=5 \mathrm{~mm}$ and $\mathrm{O}=3 \mathrm{~mm}$, the present configuration) and $\mathrm{I}<\mathrm{O}(\mathrm{I}=3 \mathrm{~mm}$ and $\mathrm{O}=5$ $\mathrm{mm})$.

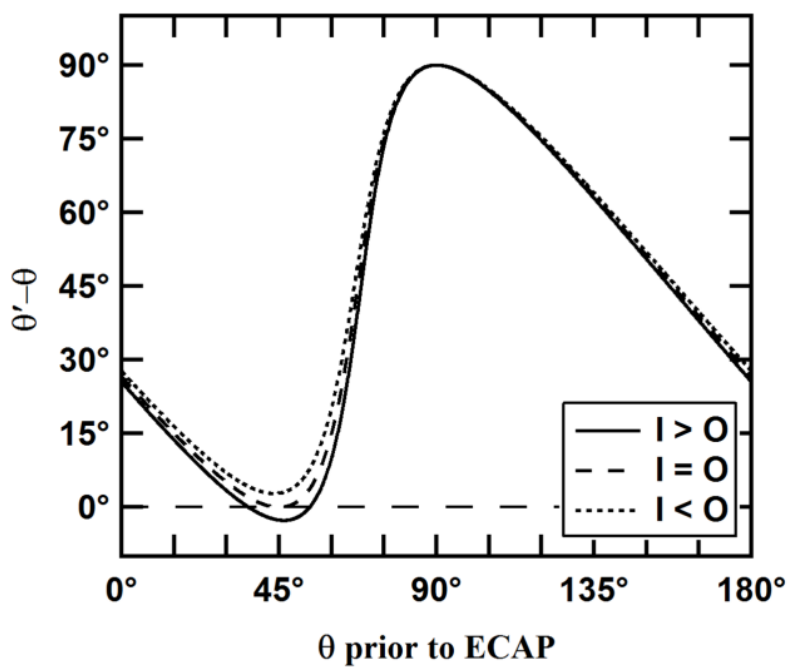

Fig. 10. Rotation angle (counter-clockwise, i.e. $\theta^{\prime}-\theta$ in Fig. 1) versus the orientation before ECAP ( $\theta$ in Fig. 1) for three different die configurations: $\mathrm{I}=\mathrm{O}, \mathrm{I}>\mathrm{O}(\mathrm{I}=5$ $\mathrm{mm}$ and $\mathrm{O}=3 \mathrm{~mm}$, the present configuration) and $\mathrm{I}<\mathrm{O}$ ( $\mathrm{I}=3 \mathrm{~mm}$ and $\mathrm{O}=5 \mathrm{~mm}$ ). 


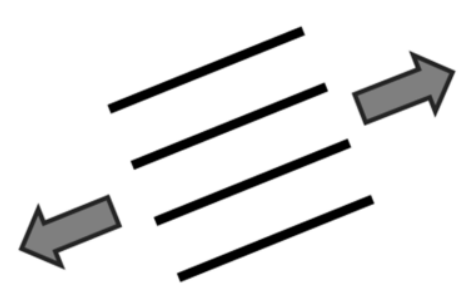

(a)

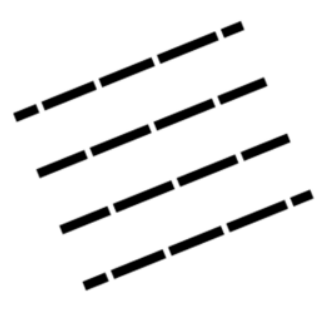

(b)

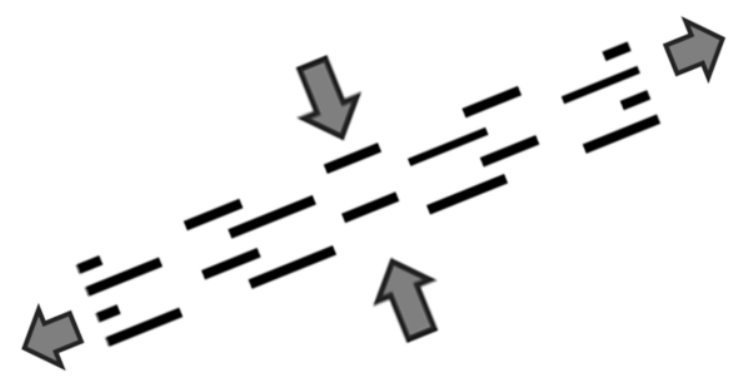

(c)

Fig. 11. Illustrated process of $\mathrm{K}_{\mathrm{III}}$ fragmentation upon lengthening: (a) lamellae subjected to tension, (b) cracking of the lamellae under tension and filling of the gap by the matrix $\alpha$ due to compression in the perpendicular direction, and (c) separation of the $\mathrm{K}_{\mathrm{III}}$ fragments and reduction in lamellar spacing.

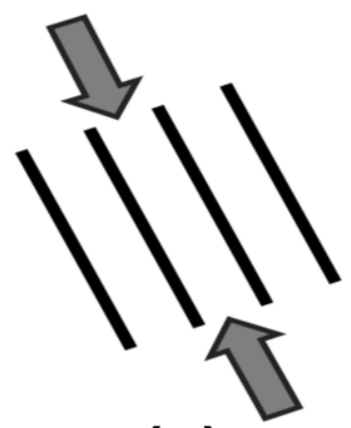

(a)

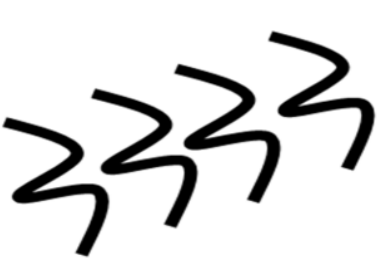

(b)

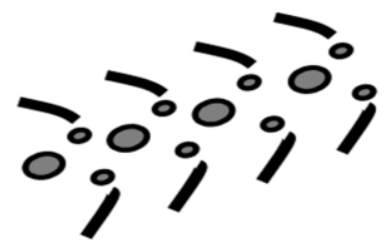

(c)

Fig. 12. Illustrated process of $\mathrm{K}_{\mathrm{III}}$ buckling upon shortening: (a) lamellae subjected to compression, (b) lamellar buckling and folding to accommodate the shortening, and (c) spheroidisation at places of high curvature. 


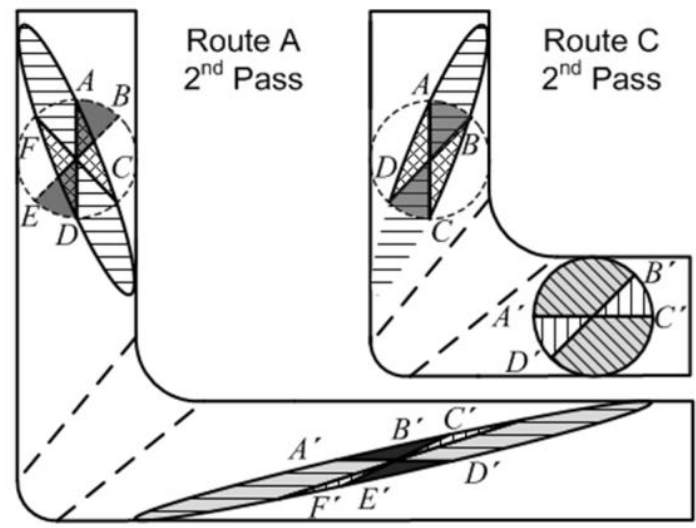

\begin{tabular}{|c|c|c|}
\hline Shortened x 1 & 目 & Lengthened $\times 1$ \\
\hline Shortened $\times 2$ & 目 & Lengt \\
\hline $\begin{array}{l}\text { Shortened + } \\
\text { Lengthened }\end{array}$ & $\mathbb{N}$ & $\begin{array}{l}\text { Lengthened } \\
+ \text { Shortened }\end{array}$ \\
\hline
\end{tabular}

Fig. 13. The geometric model applied to the second pass via route $\mathrm{A}$ and route $\mathrm{C}$, respectively. The ellipses in the entrance channels represent the elements shaped after the first pass and replaced there for the second pass. The dashed circle in each entrance channel indicates the lengthening and shortening orientations for the second pass (with the same meaning as in Fig. 8). The shapes and patterns in the exit channel represent the cumulative effects of the two passes, with the letters with primes in the exit channels tracing those in the entrance channels. 
(a)
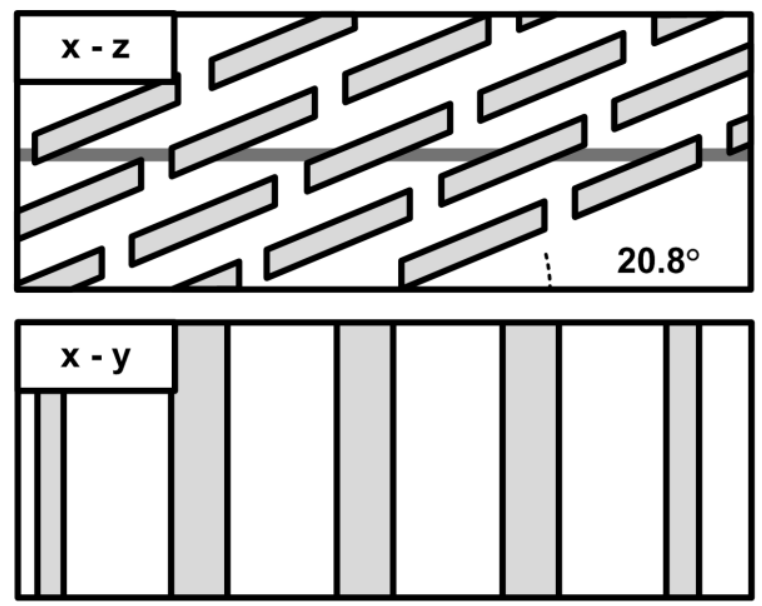

(c) After 3rd Route $B_{A}$ Pass
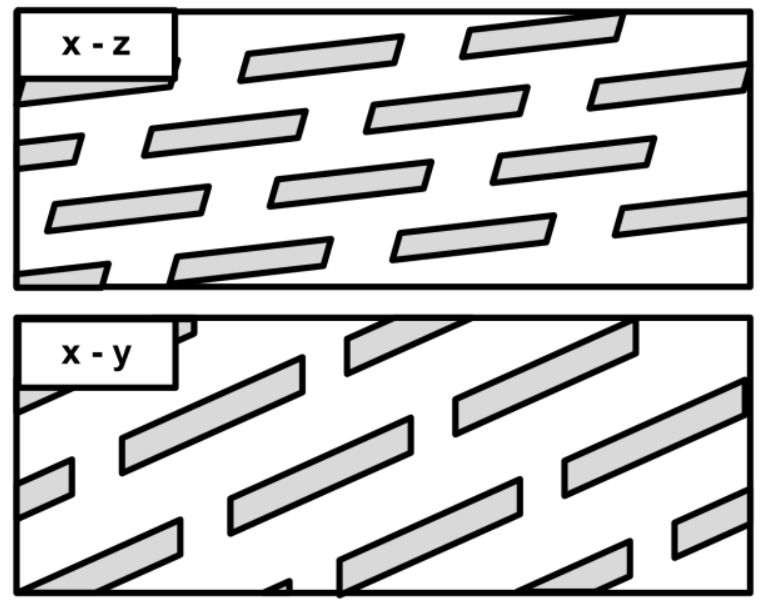

(e) After 3rd Route $B_{c}$ Pass
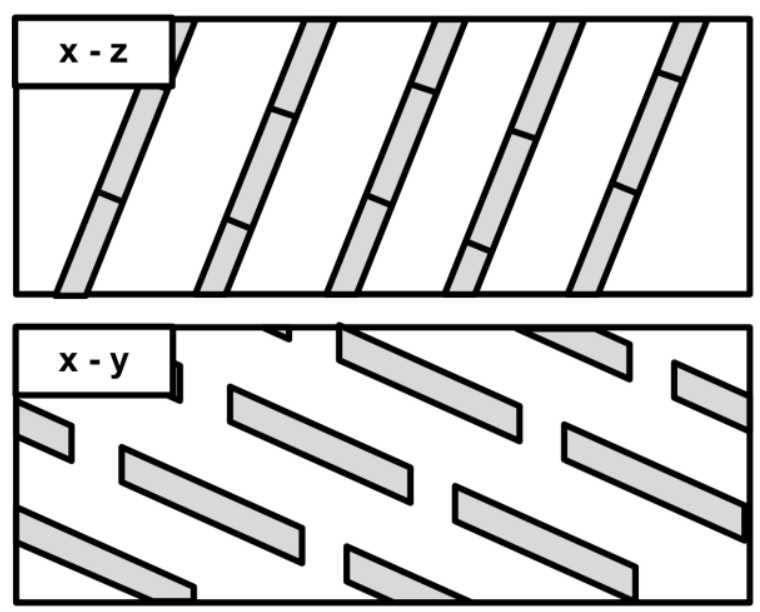

(b) 2nd Pass via Route B

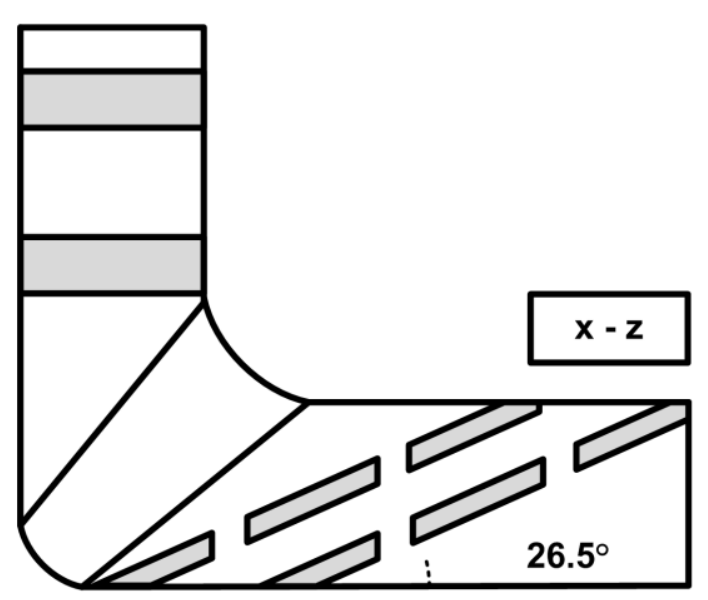

(d) 4th Pass via Route $B_{A}$

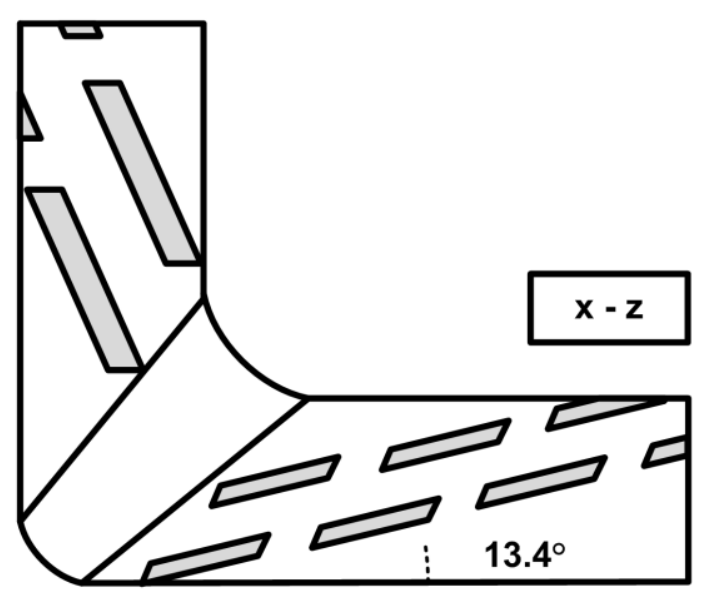

(f) 4th Pass via Route $B_{c}$

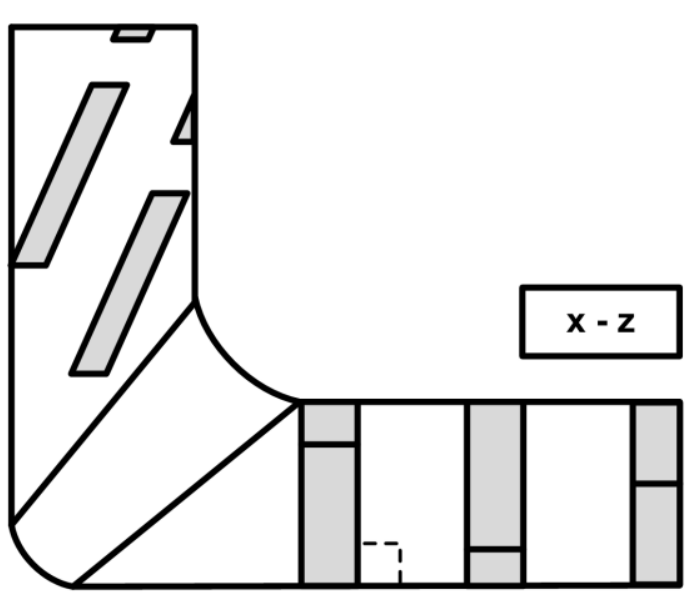

Fig. 14. Three dimensional morphologies of the fragmented $\mathrm{K}_{\text {III }}$ laths (a) after the first pass, (b) before and after the second pass via the $B$ routes, (c) after the third pass via $B_{A}$, (d) before and after the fourth pass via $B_{A}$, (e) after the third pass via $\mathrm{B}_{\mathrm{C}}$, and (f) before and after the fourth pass via $\mathrm{B}_{\mathrm{C}}$. The $x-z$ and $x-y$ views are sections at a certain $y$ and a certain $z$, respectively. 


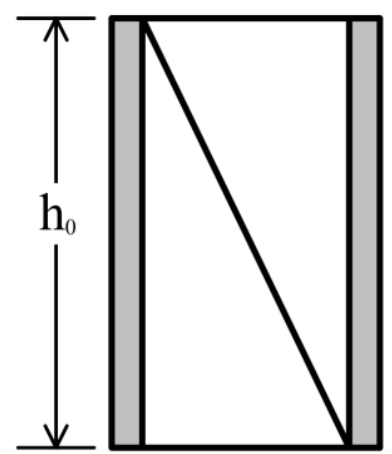

(a)

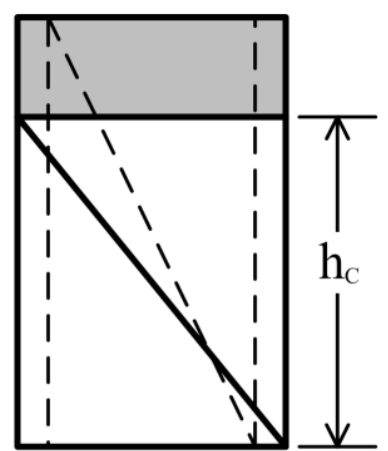

(b)

Fig. 15. The shapes of the ECAP specimen in the entrance channel (a) as-inserted and (b) after compression (before entering the shear zone), illustrating the change of orientation of the diagonal line.

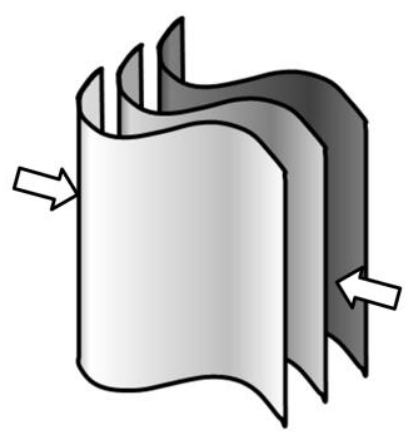

(a)

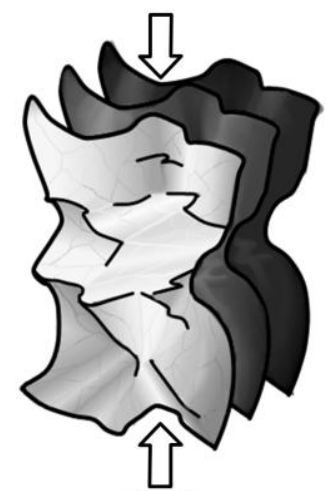

(b)

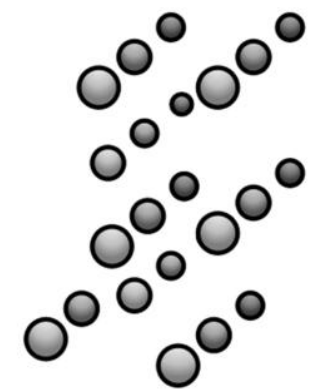

(c)

Fig. 16. Illustrated process of spheroidisation for lamellae experiencing contraction and buckling in route B: (a) initial buckling of the lamellae (b) further compression (perpendicular to the first pass) on the second pass causing the formation of undulated surfaces, and (c) spheroidisation of the peaks and troughs leading to a complete breakdown of the lamellae. 